\begin{tabular}{c|c|c|c|c|c|c|c|} 
DOI: http://dx.doi.org/10.21276/ap.covid19.2021.10.1.9 \\
Annals of Phytomedicine: An International Journal \\
http://www.ukaazpublications.com/publications/index.php \\
Print ISSN : 2278-9839
\end{tabular}

\title{
Nutraceuticals: Potential prospect for COVID-19 management
}

\author{
Nupur Mehrotra and Kaustubh Jadhav
}

Department of Biochemistry, SVKM's Mithibai College of Arts, Chauhan Institute of Science and Amrutben Jivanlal College of Commerce and Economics (Autonomous), Vile-Parle (West), Mumbai-400056, Maharashtra, India

\section{Article Info}

Article history

Received 10 April 2021

Revised 28 May 2021

Accepted 29 May 2021

Published Online 30 June 2021

\section{Keywords}

SARS-CoV-2

COVID-19

Nutraceuticals

Immunomodulators

Immunestimulators

\begin{abstract}
Across the globe, the SARS-CoV-2 infection or the COVID-19 pandemic has claimed thousands of fatalities every day. Researchers have been able to produce vaccines, however, it is as recent as December 2020, that the use of the same has been initiated, though all such products are still being studied for their longterm safety and efficacy, since the virus is fast mutating. The discovery of specific antiviral against SARS-CoV-2 also has not seen the light of the day.

Thus, the strategy to control the pandemic is largely focused on use of supplements and nutraceuticals, mostly plant based. These products can be used as preventive as well as to mitigate the symptoms and thereby provide therapy. Such products are ahead of other pharmacological candidates, as they are comparatively cheaper, easily available locally and the adverse reactions are negligible, if any. The nutraceuticals being used work as immunomodulators, thereby manipulating the immune response in mitigating the infection. They assist in regulating not only inflammation but also mediate the immune response to cater to preventing damage to respiratory system, the major concern in COVID-19. Many nutraceuticals have been found to benefit the disease conditions under various viral attacks, though detailed study on SARS-CoV-2 is underway for many such products.

The current review focuses on presenting the nutraceuticals which have been evaluated for their antiviral properties. The antiviral effects are mediated through direct inhibition to the entry of the virus into host cells or through the indirect modulation of the immune system, thereby enhancing the recovery of patients. With their proven potential towards many disorders/diseases, their medicinal potential could be the sunlight in providing an end to the 2020 COVID-19 pandemic.
\end{abstract}

\section{Introduction}

Wuhan, China, since December 2019, has been a city known to one and all as it was the city wherein the SARS-CoV-2 pandemic originated. The coronavirus infection termed COVID-19 is caused by the virus leading to a severe acute respiratory syndrome. On 11 March 2020, the World Health Organization (WHO) declared COVID-19 as a pandemic. Globally the virus has infected citizens of more than 200 countries across all five continents. Clinically, patients depict a spectrum of severity ranging from being asymptomatic to a few developing severe pneumonia, leading to acute respiratory discomfort and sometimes leading to a multiorgan failure (Guan et al., 2020). It has been observed that the initial symptoms in most cases are hypoxemia and dyspnea, progressing towards mild respiratory syndrome requiring $\mathrm{O}_{2}$ support. However, patients with comorbidities, rapidly progress towards acute respiratory distress syndrome (ARDS), with complications as metabolic acidosis, disseminated intravascular coagulation, septic shock, coagulation dysfunction developing

\section{Corresponding author: Dr. Nupur Mehrotra}

Department of Biochemistry, SVKM's Mithibai College of Arts, Chauhan Institute of Science and Amrutben Jivanlal College of Commerce and Economics (Autonomous), Vile-Parle (West), Mumbai-400056, Maharastra, India

E-mail: nupur.mehrotra@mithibai.ac.in

Tel.: +91-9833452122

Copyright $(\odot) 2021$ Ukaaz Publications. All rights reserved.

Email: ukaaz@yahoo.com; Website: www.ukaazpublications.com multiple organ failure, which is fatal (Li et al.,2020; Hong Kong Centre for Health Protection, 2020; Gao et al., 2020). Though, the susceptibility to the virus is maximum in senior citizens with comorbidities, however, all age groups are vulnerable to the viral infection.

As of $9^{\text {th }}$ April 2021, 133,552,774 confirmed cases have caused more than 2,894,295 deaths (WHO, 2021).

With more than a year into the pandemic, a vacuum still exists on the use of any single antiviral drug selective in controlling the infection, and across nations, different combinations of antivirals are being used. The successful combinations are mainly the ones that target the molecular pathways of SARS and MERS (Cao et al., 2020). The most successful amongst all antiviral has been Remdesivir, which has been successful in shortening the period of discharge of COVID-19 patients who are hospitalized (Biegel, et al., 2020). Patients reporting severe COVID-19 pneumonia, are prescribed corticosteroids and have benefitted as it impedes the cytokine storm to delay disease progression toward a severe form (Russel et al., 2020). The cytokine storm which is an erratic and abnormal immune response has been outlined as a cause of driving COVID-19 patients to ARDS, fibrosis, and widespread lung damage.

Different strategies can be worked upon to prevent severity of SARS-CoV-2 infection (Figure 1). One could be to involve exalted systemic inflammatory parameters, resulting from an abnormal rise in the levels of cytokines as interleukin (IL)-6, IL-8, C-reactive 
protein, and tumor necrosis factor, (TNF) (Mehta, et al., 2020). A humanized anti-interleukin-6-receptor (IL-6R) monoclonal antibody tocilizumab inhibits interleukin-6 (IL-6) signaling and is under clinical trials (Francesco et al., 2020). SARS-CoV-2 infection initiates in the lungs where the virus replicates and causes inflammation. The direct inflammasome activators comprise reactive oxygen species (ROS) associated with succeeding blood dissemination, due to adaptive immune response against oxidative stress (Laforge et al., 2020;
Cecchini and Cecchini, 2020). The cytokine storm, blood clotting, and hypoxia associated with SARS-CoV-2 infection, are associated with oxidative stress which acts as the trigger. Studies suggest that the virus interrupts the equilibrium between the transcription of nuclear factor kappa-light-chain-enhancer, thereby leading to higher expression of cytokines and activation of nuclear factor erythroid2-related factor 2 (Kirchei, et al., 2020; Kandasamy, 2021; Carcaterra, and Caruso, 2020; Olagnier, 2020).

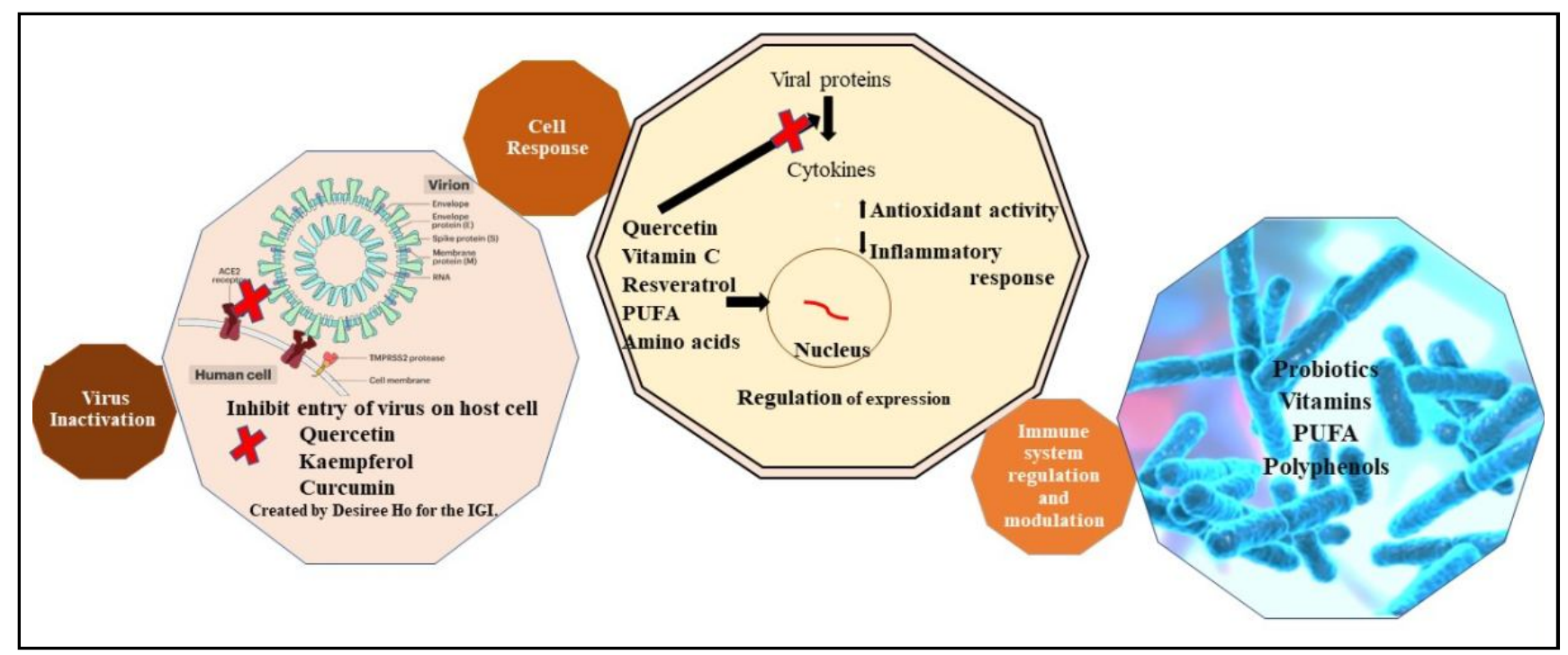

Figure 1: Suggstive pathways for antiviral activity against SARS-CoV-2.

The body's immune system arms, viz., the innate and adaptive responses, both help in protection against any infection. The innate immune responses are triggered almost instantly, followed by the adaptive response, as the latter being specific requires 6-8 days to elicit. With a SARs-CoV-2 infection, the host's innate immune responses are upset which leads to the aggravation of respiratory syndrome, reasons for which is still being probed (Prasad et al., 2020). Further, following initial infection, the pro-inflammatory cytokines secretion is also dysregulated (Cheng et al., 2020) which leads to the cytokine storm. An increase in the number of activated $\mathrm{Tc}$, Th, and plasma B cells followed by increased secretion of IgG and IgM is reported in mild cases, in contrast to a fall in Th, Tc, NK, and B cells in case of severe infection (Thevarajan et al., 2020). An increase in the neutrophil to lymphocyte ratio (NLR) as well as C-reactive protein levels are efficient biomarkers of systemic inflammatory responses (Qin et al., 2020; Wang et al., 2020). Effectively, it has been observed that both innate and adaptive responses are impaired, thus triggering complications as pulmonary injury culminating into acute respiratory distress syndrome followed by multiple organ failure and fatality (Prompetchara $e t$ $a l ., 2020)$. Thus, it is rational to consider the candidature of agents which work to relieve oxidative stress as well as the dysfunction of inflammation induced endothelium, as a preferential target for COVID-19 prevention and therapy.

\section{Nutraceuticals}

During the pandemic, people worked towards strengthening their immunity as preventive therapy. This brought into light the use of alternative and non-conventional therapy modalities into lime-light, wherein the use of medicinal plant-based nutraceuticals has been the most favored. 'Nutraceutical' derived from 'nutrition' and 'pharmaceutical' was a term coined by DeFelice, in 1989. Kalra, (2003) defined nutraceuticals as food or its part providing medical or health benefits, including the prevention and/or treatment of a disease. Nutraceuticals not only provide their basic nutritional value but additionally possess several health benefits (McClements, et $a l ., 2009)$. Nutraceuticals are often confused with dietary supplements, as both are used for improving health. The difference is that nutraceuticals not only supplement the diet but aid in prophylaxis and /or therapy of disorders/ diseases (Kalra, 2003), while supplements mainly enhance the dietary intake of nutrients. Within the spectrum of nutraceuticals included are natural foods rich in nutrients as garlic, spirulina, etc., or a particular component as omega-3 oil from salmon. Thus, this broad umbrella of nutraceuticals ranges from isolated nutrients to genetically engineered foods to herbal products and also processed foodstuffs as cereals and soups. The potential nutritional benefit accompanied by therapeutic effects with presumed safety has led to considerable interest in nutraceuticals (Rajasekaran et al., 2008).

Nutraceuticals are classified (Verma and Mishra, 2016) into many types or styles, some of which are represented below and in Figure 2:

(A) Traditional nutraceuticals, which include the ones sourced in their natural form, e.g., lycopene from tomatoes, carotenoids from carrots, omega-3 fatty acids in salmon, etc. Further, subclassification is based on: 


\section{(i) Chemical constituents}

(a) Nutrients: The basic nutrients as carbohydrates, amino acids, fatty acids, vitamins, have well-defined metabolic functions and many health benefits like the omega-3 fatty acids from salmon, influences inflammatory responses (Chanda et al., 2019).

(b) Phytochemicals: A repertoire of phytochemicals are present in medicinal plants providing health benefits. Carotenoids enhance the overall immune system majorly by increasing natural killer cell count.

(ii) Probiotic microorganisms: Probiotic microorganisms can accelerate absorption and metabolism in the intestine and facilitate removal of toxic flora facilitating a friendly gut environment. They possess suitable nutrients to counter several ailments and impact the microflora with better retention.

(iii) Nutraceutical enzymes: Enzymes, the biocatalyst hasten metabolic rate and are especially very useful for disorders associated with GIT whether GERD (gastroesophageal reflux disease), constipation, or ulcerative colitis.

(B) Nontraditional nutraceuticals: Foods enriched with supplements or crops that are biotechnologically designed to lift the nutrient content like the genetically modified rice and broccoli with higher content of $\beta$-carotene and vitamins, respectively

(i) Fortified nutraceuticals: Additional supplementation in natural foods like folic acid, calcium, and iron, fortified flour or cholecalciferol fortified milk

(ii) Recombinant nutraceuticals: Using fermentation technology and RDT tools for increasing useful components in foods like bread and cheese.

(C) Classification based on mechanism of action: Classification based on specific beneficial properties as anti-inflammatory, antimicrobial, antioxidant, antidiabetic, etc.

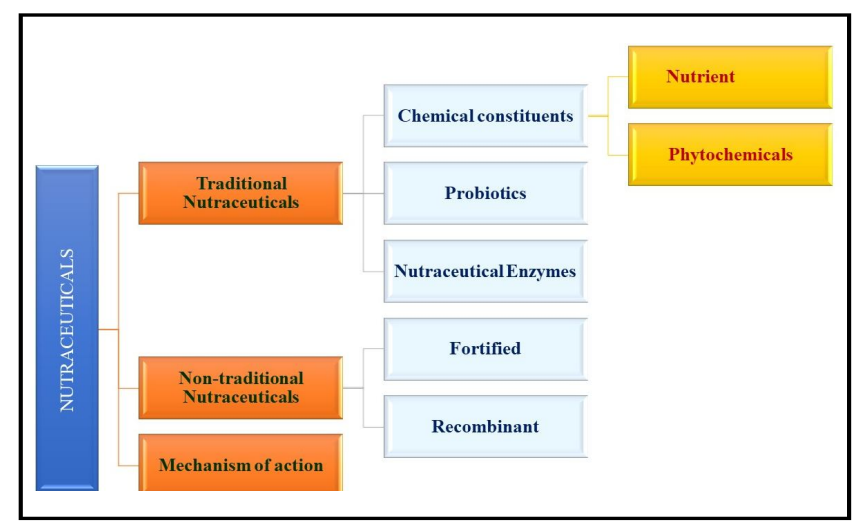

Figure 2: Classification of nutraceuticals.

As the buzzword in the battle against COVID-19 is 'immunity', a multifold increase in the demand for nutraceuticals has been noticed across the globe. As per 'Valuates reports', the nutraceuticals market is primed to expand by $\$ 180.38$ billion, globally, during 2020 2024, advancing with $9 \%$ compound annual growth rate (CAGR). The present review focuses on some of the nutraceuticals being considered for not only the prevention of SARS-Co-V2 infection but also for its therapy. Our focus is to provide the immunological basis for the use of nutraceuticals, especially during viral infections.

\section{Nutraceuticals and COVID-19}

\subsection{Polyunsaturated fatty acids (PUFA)}

Omega-3 PUFAs have been investigated for advantageous antiviral effects (Zhang et al., 2020), and the ones studied extensively include docosahexaenoic acid (DHA) and eicosapentaenoic acid (EPA), found in high amounts in fish (Lordan et al., 2020). Another source is algae, which are not only rich in DHA and EPA but are also a rich source of angiotensin-converting enzyme inhibitor peptides (Szabó et al., 2020; Saha et al., 2018). Also found in algae are the sulfated polysaccharides, phycobiliproteins, and calcium-spirulan, known to possess antiviral properties which can prove beneficial during SARS-CoV-2 (Ratha et al., 2021).

It has been observed that sepsis and ARDS hold a lot of concern during COVID-19 infection and the n-3 PUFAs nutritional status can be useful in combating the same (Das, 2019). A study in Wuhan of 82 deceased COVID-19 patients reported that respiratory failure due to ARDS leads to $69.5 \%$ death rate while $28.0 \%$ of deaths were due to sepsis or multi-organ failure (Zhang et al., 2020).

On a randomized clinical trial with 24 patients, a meta-analysis on the effects of omega-3 fatty acids on ARDS and sepsis was conducted and it was found that these fatty acids as enteral nutrition helped in the elevation of disease conditions (Chen et al., 2018).

Omega-3-PUFAs, especially, have shown to be protective against COVID-19 infections due to their capability for the biosynthesis of protectins and resolvins, termed as endogenous specialized proresolving mediators (SPM), which have shown potential to settle inflammation and infection due to viral lung infections by RNA viruses (Christopher et al., 2014; Sandhaus and Swick, 2020). Amongst the many studied SPM's, protectin D1 affects the viral replication of $\mathrm{H} 1 \mathrm{~N} 1$ and, thus speeds up recovery (Morita $e t$ al., 2013). The other immunological advantages associated with SPM's are: (i) inhibiting the release of pro-inflammatory cytokines, enhancing phagocytosis by macrophages (Serhan, 2014); (ii) promotion of B lymphocytic activities against the virus (Ramon et al., 2014; Panigrahy et al., 2020). Regidor et al. (2020) have put forward the claim that SPM could contribute to resolving the COVID19 associated cytokine storm and pulmonary inflammation. Further, the adversities in patients with co-morbidities have been correlated to deficiencies of SPM by Pal et al. (2020). Husson et al. (2016) reported that the effectiveness of PUFA against bacterial and viral infections is dependent not only on the causative agent but also on the dosage and the timing, of the therapy, though Skarke et al. (2016) was apprehensive of the increase in SPM levels post-ingestion of fish oils in response to acute inflammation in humans.

Another reason for use of omega- 3 fatty acids against COVID-19 is its potential use as a prophylactic and therapeutic anticoagulant, along with its properties to be an antithrombotic (Tsoupras et al., 2020; Bikdeli et al., 2020).

Clinical trials are underway to evaluate the anti-inflammatory activity of Icosapent ethyl (VascepaTM) a, highly purified derivative of EPA, while trials intending to investigate the anti-inflammatory properties of EPA's, in general, are in preparatory stages (Amarin 
Corporation and HLS Therapeutics, Inc, 2020; S.L.A. Pharma AG, 2020; Mahmoud Abulmeaty, 2020).

\subsection{Arginine}

A synergistic action of arginine in conditions like high temperature and acidic $\mathrm{pH}$ levels depicts that the amino acid potentially possesses virucide activity inactivating enveloped viruses (Ohtake et al., 2010; Meingast et al., 2020). Inactivation of herpes simplex virus type 2 (Tsujimoto et al., 2010) and influenza A virus (Yamasaki et al., 2008) was the result obtained when arginine solution was administered in the patient suffering from these viral infections. Ikeda et al. (2012) postulated that arginine may interact with multiple viral sites affecting viral envelope. An in vivo study on the effect of arginine on influenza virus has revealed that arginine can be used in intranasal spray due to its low cytotoxic effect (Ikeda, 2010). Zhang et al. (2015) demonstrated the use of arginine to reduce airway inflammation in lung cells of NC/Nga mice having asthmatic symptoms, thereby causing improved health of an organism. Yamasaki et al. (2011) examined various amino acids like $\mathrm{N} \alpha$-Cocoyl-L-arginine ethyl ester (CAE), arginine cocoate, and alkyloxyhydroxylpropylarginine against HSV type 1 and 2, poliovirus type -1 and influenza $A$ virus. The results indicated the therapeutic action of CAE against HSV-1. Early steps of viral replications are not affected by arginine but it is required for the expression of the later viral functional genes like coat protein synthesis and formation of virions, a complete infectious particle. This was suggested by Butorov (2015) in continuation with the suggestion, that the absence of essential amino acids like arginine may result in the inability of the viruses to synthesize proteins resulting in inhibitory activity.

Many clinical studies have concentrated on a virucidal activity as a therapy in COVID-19 patients. One of the approaches is to disrupt the interaction between host and virus through restriction of amino acids for example arginine. Hence, a reduction in arginine can have potent action against COVID-19 infection and other viral-borne diseases (Joseph et al., 2021).

\subsection{Glutamine}

Glutamine is present in the human system in the concentration of about 500-900 $\mu \mathrm{mol} / 1$ in the free form (Pierre et al., 2013). Glutamine was found to be immunosuppressive and anti-inflammatory in the asthmatic murine model. Such immunomodulatory activity is due to the inhibition potential of arginine towards the recruitment of neutrophils in the airways (Lee et al., 2012). In vivo study on ventilator-induced lung injury mice, by Lai et al. (2014) demonstrated that glutamine reduces the damage of lung cells and lung edema as it inhibits cytokine production and neutrophil entry into the lungs. Beneficial effects of exogenous glutamine were also seen on asthma, acute respiratory distress syndrome, and lung cancer (Oliveira et al., 2016). These findings suggest the potential health benefits of glutamine in the treatment of COVID-19 patients.

On interacting with pathogens, $\mathrm{T}$ lymphocytes are triggered in the presence of glutamine (Klysz et al., 2015). It is observed that glutamine is important for immune cell proliferation (Carr et al., 2010). The proliferation and activation of $\mathrm{T}$ lymphocytes are related to the uptake of glutamine through transporter ASCT2 and the activation of naive $T$ lymphocytes is associated with the rapid glutamine uptake, which requires the amino acid transporter
(Nakaya et al., 2014). Impaired numbers and functions of the transporters lead to weakening the activities of immune cells (Sinclair et al., 2013).

\subsection{Bioactive proteins and peptides}

Bioactive peptides are classified by their action and their binding capacity to micronutrients. Some anti-inflammatory activities of peptide fractions can be obtained from fermented milk with specific Lactobacillus plantarum strains (Udenigwe and Aluko, 2012). The pharmacological activities of peptides include them being antioxidant, anticancer, hypocholesterolemic, hypotensive, antidiabetic, and antimicrobial (Lammi et al., 2019). $\beta$-casein in animal milk (Kibangou et al., 2005), phosvitin in egg yolk (Zhong et al., 2016), protein hydrolysates of fish skin and bones (Walters et al., 2018), common beans plants (Carrasco-Castilla et al.,2012) and soybean milk (de Oliveira et al.,2015) are phosphorous peptides that show a high iron-binding ability. In vitro studies have shown that bioactive peptides are potential anti-hemolytic, antimutagenic, antioxidant, and antimicrobial agents (Rodríguez et al.,2018). Also, these bioactive peptides are found to disrupt viral spike proteins of HIV. According to Udenigwe and Aluko (2012), bioactive peptides from food are widely considered for their increased potential for the improvement of human health and prevention of chronic diseases. Furthermore, phytic acid in soybean is a potent inhibitor of the absorption of nonheme iron in humans (Hurrell et al.,1992). Hydrolyzed rice bran proteins with flavourzyme and alcalase demonstrated an iron-chelating property, which increases on hydrolysis (Foong et al., 2015). Such findings, lead to prove that the iron-chelating property of some foods finds application to prevent viral replications and halt pro-inflammatory and oxidative pathways.

\section{$3.5 \beta$-Glucans}

Beta-glucan is naturally present to a high extent in the plant cell walls as wheat, barley, and oats, besides its presence in cell walls of baker's yeast, many funguses, and in some microorganisms. The predominant beneficial properties of $\beta$-glucan include its use for the prevention as well as the treatment of digestive diseases, as antitumor, anti-inflammatory, and an immune modulator. These pharmacological actions are dependent on its molecular weight, size, conformation due to side branching and its solubility (Kumar, $2020)$. Fungal and yeast $\beta$-glucans comprise of $(1,6)-\beta$-linked side chains on a $(1,3)-\beta$-linked backbone and hold immense immunemodulating effects (Stier et al., 2014). Vetvicka and Vetvickova (2014 and 2016) have described the role of $\beta$-glucan in increasing phagocytosis, and production of IL-2, IFN $\gamma$, and antibodies.

Murphy et al. (2020) demonstrated the utility of $\beta$-glucans in alleviating lung infections in ARDS. The challenge, however was the reliability and repeatability along with the purity of the compound due to being contaminated with microbes which can adversely affect the lungs.

$\beta$-glucans, exert beneficial effects on the defense system by being activators of macrophages, neutrophils, and NK cells (De Marco et al., 2020). The susceptibility and the severity of upper respiratory tract infections (URTIs) were found to decline (Dharsono et al., 2019). It has proved its potential as antiviral against infections by HSV 1 (Urbancikova et al., 2020) and the influenza virus (Vetvicka and Vetvickova, 2016). 
McCarty and Di Nicolantonio (2020) explained that $\beta$-glucan can enhance interferon type 1 responses against influenza as well as coronavirus, both being RNA viruses, while the reduction in COVID-19 related morbidity and mortality has also been suggested (Geller and Yan, 2020; Murphy et al., 2020).

\subsection{Ascorbic acid (Vitamin C)}

L-ascorbic acid, (AA), to the common man, is vitamin $\mathrm{C}$, a water-soluble vitamin with its immense functions in different biochemical mechanisms. Humans for their basic requirement require the daily intake of vitamin $C$ through their meals as they are unable to synthesize it in vivo in absence of L-gluconolactone oxidase, the enzyme required for its biosynthesis from D-glucose (Corti et al., 2010). It is popularly called the "scavenger molecule", due to its efficient antioxidant activities and potential to scavenge the physiological cell metabolism, viz., free radicals and ROS along with products associated with inflammation and oxidative damage (Carita et al., 2020; Moser et al., 2016). Its role is vital in the regulation of many biological pathways like the biosynthesis of corticosteroids, carnitine, catecholamines, collagen, oxidation of tyrosine, and epigenetic modifications (Carr and Maggini, 2017).

AA's role as an immune-modulator, thereby affecting innate and acquired immunity are well known (Molina et al., 2014). Pathogenic infection damages body tissues affecting innate immune responses predominantly (Franz et al., 2011) and is generally associated with the body's oxidative capacity to combat the pathogens. Hemil and Suonsyrj (2017), reported the potential of $1000 \mathrm{mg}-2000 \mathrm{mg} / \mathrm{day}$ vitamin $\mathrm{C}$, not only in management but also its preventive role in viral disease management. It was further suggested that an $85 \%$ reduction in major symptoms was observed in ascorbic acid-treated individuals as compared to those on most accepted medicines for cold and flu medication. The significance of therapy using vitamin $\mathrm{C}$ finds ground on the understanding that it is associated with the structure, and function of nasal and gastric mucosa, controlling the mucus secretion, and maintaining the integrity of both- outer and inner epithelium. Thus, the vital role of vitamin $\mathrm{C}$ in strengthening the immune barriers against respiratory tract viral infections (Calder et al., 2020). Based on studies by Cai et al. (2015), on H1N1, it has been indicated that vitamin $\mathrm{C}$ can inhibit the SARS-CoV-2 induced complication of COVID-19. The role of alpha and beta interferons significantly reduces the viral infiltration into the lungs, thereby reducing inflammatory response (Boretti and Banik, 2020). Similar results have also been noted for influenza-infected animals (Li et al., 2006). Further, cytokine production is modulated, with a decrease in histamine levels, augmenting T-and B-lymphocytes differentiation and proliferation followed by increasing antibody levels (Carr and Rowe, 2020).

A dose of $2000 \mathrm{mg} /$ day is the upper tolerable limit for this vitamin (Krinsky et al., 2000) as higher doses lead to gastrointestinal disturbances, though tolerability is higher through intravenous administration, which shows significant reductions in symptoms commonly observed in patients with SARS-CoV-2 infection (Arvinte et al., 2020). Coronavirus infection leads to microthrombi formation and coagulopathy which can be restored by early vitamin $\mathrm{C}$ infusions wherein expression of platelet-endothelial adhesion molecules and endothelial surface P-selectin, is inhibited (Song et al., 2020). Intravenous vitamin $C$ administration has been seen to even reduce the notably high levels of D-dimer noted in COVID -19 patients (Hiedra et al., 2020)

A meta-analysis study by Hemilä and Chalker (2019), reported that the supplementation with vitamin $\mathrm{C}$ reduced the duration of stay by $7.8 \%$ at intensive care units, which was further shortened by $8.6 \%$ when the dose of vitamin $\mathrm{C}$ was as high as 1-3 g/day, along with shortening the duration of ventilation by $18.2 \%$. Liu, et al. (2020), initiated a clinical trial with 56 critically ill COVID-19 patients. They were administered vitamin $C$ intravenously at the rate of $12 \mathrm{~g} / 12 \mathrm{~h}$ over 7 days and reported a promising reduction in mortality rates, accompanied by a significant reduction in IL-6 levels. Through, such studies, there appear to be convincing reports of the effectiveness of this vitamin in COVID-19 infection treatment.

\subsection{Curcumin (Curcuma longa L.)}

Curcuminoids are polyphenolic compounds obtained from the dried rhizomes of Curcuma longa. Amongst, the many in the family, E, E-1,7-bis-(4-hydroxy-3-methoxyphenyl)-1,6-heptadiene-3,5dione, or curcumin, is a yellow pigment and is the most studied phytochemicals. Curcumin is known globally to be an excellent anti-inflammatory (Fadus et al., 2017), antimicrobial (Manoharan et al., 2020), and an antioxidant (Zahedipour et al., 2020).

Verma (2020) studied the effect of curcumin on the Zika and chikungunya virus and found that the viruses lost their infectivity. Earlier, Pang (2015) had suggested that antiviral properties can be attributed to the downregulation of the Ang II type 1 receptor and upregulation of the Ang II type 2 receptor, leading to a higher AT2 /AT1 receptor ratio, in the curcumin group as against control. Further, the phagocytic activity is hampered due to a decrease in macrophage populations. Tozsé et al., (2016), observed a reduction in the secretion of IL-1, in presence of curcumin due to the inhibition of the activation of NLRP3 inflammasome.

In vitro studies demonstrate a greater binding affinity of curcumin towards Mpro of SARS-CoV-2 in comparison to nelfinavir, one of the best synthetic antivirals (Khaerunnisa et al., 2020; Runfeng et al., 2020; Tallei et al., 2020). It also irreversibly inhibits aminopeptidase N/CD13, thereby preventing the cellular binding via $\mathrm{CD} 13$ which can prevent the infection of coronavirus (Shim et al., 2003). Molecular docking studies depict that curcumin can inhibit SARS-CoV-2 entry into target cells as it can bind to the viral nucleocapsid and the nsp 10 proteins, with high affinity (Suravajhala $e t$ al., 2020).

Besides its direct antiviral activity, studies suggest that cellular signaling in response to infection with coronavirus can also be modulated, thereby reducing the disease risk. Some such mechanisms involve inhibition of viral replication as well as the synthesis of the viral protease (Zahedipour et al., 2020). The lung tissue damage resulting from coronavirus infection can be reduced by the anticytokinetic properties of curcumin, which modulates inflammation. Amongst the many mechanisms identified, Avasarala et al. (2013), suggested that IL-1, IL- 8 , and TNF- $\alpha$ along with transcription factors nuclear factor kappa B (NFkB) and activator protein-1 (AP-1) are inhibited which restricts damage to lung tissue during viral infections affecting the respiratory system.

Curcumin is largely non-toxic, non-mutagenic, nongenotoxic, even on being consumed as high oral doses over extended periods $(6 \mathrm{~g} /$ 
day for up to 49 days) (Soleimani et al., 2018) and, thus has wide acceptability in the food industry. However, it has been reported to have low availability with a rapid metabolic rate which may limit its clinical impact. Being water-insoluble at physiological $\mathrm{pH} 7$ limits its systemic bioavailability (Lopresti, 2018). Thus, the emergence of several proprietary nutraceutical formulations like curcumin-lecithin-piperine curcumin-phosphatidylserine, and formulas along with sesquiterpenoids such as Biocurcumax ${ }^{\mathrm{TM}}$ (Jamwal, 2018). The addition of carrier molecules in these combinations overcome low bioavailability, increase uptake and solubility and facilitate better cellular metabolism. The probable benefits of curcumin can further be evaluated by encapsulating it in nano-formulations thereby further enhancing its viral activity (Praditya, et al., 2019).

\subsection{Polyphenols}

Polyphenolic compounds from plant foods and their extracts are well-known antioxidants. They are also found to possess antimicrobial and antiviral activities. These can be divided into phenolic acids and flavonoids. A study by Calvo et al. (2017) explored in vitro antiviral capacity of different polyphenols and it was shown that epigallocatechin gallate and delphinidin inhibit West Nile and Zika virus infections. Among the polyphenols, curcumin was found to bind to the target receptor on SARS-CoV-2. (Utomo et al. 2020). This evidence can be used as a therapy against the virus. Also, curcumin in combination with glycyrrhizic acid and vitamin $\mathrm{C}$ promotes interferon production to regulate the inflammatory response, which can be used for immune modulation during SARSCoV-2 infections (Chen et al.,2020). It has also been suggested that dietary intake of "black tea" which is rich in protocatechuic acid, punicalagin, theaflavin gallate, kaempferol, and aflavin digallate can improve the resistance to fight against COVID-19 virus in the early stages of human infection (Bhatia et al.,2020). Furthermore, tannins like punicalin, tercatain, and pedunculagin were found to be interacting with catalytic dyad (Cys145 and His41) and receptor binding site of COVID-19 main protease enzyme, thereby showing successful inhibition of the enzyme protease of novel COVID-19 (Khalifa et al.,2020). Besides, riboflavin, cyanidin, daidzein, and genistein are potent inhibitors of the main protease and RNAdependent RNA polymerase of COVID-19 (Pendyala et al.,2020). The therapeutic strategy for COVID-19 was also exhibited by the hesperidin, lepidine E class of polyphenols. Yamada et al. (2009) and Bedoya et al. (2016) have revealed the efficacy of hydroxytyrosol in the treatment of viral disease as influenza.

\subsection{Quercetin}

Quercetin is a flavonoid belonging to the flavanol category largely present in different fruits and vegetables like tea, grapes, onions, tomatoes, and shallots, along with medicinal plants like Hypericum perforatum, Ginkgo biloba, and many barks, seeds, nuts and flowers. The efficiency of quercetin glycoside is found to be much more than other quercetin forms (Li et al.,2016). The basic biological actions of quercetin are antioxidant, anti-inflammatory, and antiviral, elicited due to its potential of inhibition of lipid peroxidation, aggregation of platelets, macrophagic lipopolysaccharide-induced tumor necrosis factor production, and production of lipopolysaccharide-induced IL-8 in lungs (Martínez-Flórez et al., 2018; Mlcek et al.,2016). Johari et al. (2012) demonstrated quercetin to be effective against the mosquito-borne disease,
Japanese encephalitis (JE), whereas Bachmetov et al. (2012) found its activity against type- 2 dengue virus and hepatitis $C$ viruses. Glucuronide derivative quercetin-3-O-D-glucuronide (Fan et al.,2011) and rhamnoside derivative, quercetin 7-rhamnoside are found to be effective against porcine epidemic diarrhea virus and influenza-A virus, respectively (Quiles et al.,2020). Also, quercetin has an iron-binding capacity, and it is shown that it has more affinity towards $\mathrm{Fe}^{+2}$ than $\mathrm{Fe}^{2+}$ chelator, ferrozine. This evidence demonstrates the usefulness of quercetin for COVID-19 treatment due to its antioxidant nature, anti-inflammatory, and iron-binding ability (Xu et al., 2019). In vitro study on the effect of hydroxyquercetin on transportation of zinc shows its chelation activity. The same could be linked to anti-inflammatory response in vivo elicited by activation of $\mathrm{T}$ cells which leads to a decrease in IL-2 induced Th1 differentiation. In athletes into cycling, Nieman et al. $(2007,2010)$ demonstrated that if $3 \mathrm{~h}$ of cycling was done, immunomodulatory effects of quercetin supplemention were observed when compared with levels before, during, and after cycling in winter. It indicated a lower incidence of upper respiratory tract infection (URTI). Quercetin has been known to enhance high-fat diet-induced inflammatory response and cytokine secretion. (Stewart et al.,2008). In vitro studies on immunomodulatory effects of quercetin have revealed its inhibitory action on the production of interleukin (IL8) and TNF-alpha in lung and macrophages, respectively (Geraets et al.,2007; Manjeet and Ghosh,1999). Such findings prove the potential of quercetin as immunostimulatory and related to Th1 derived cytokine as interferon-gamma and Th2 derived cytokine-like IL-4. In SARS-CoV infection nod-like receptor (NLR) proteins develop inflammation with the help of regulators like pathogen-associated molecular patterns (PAMP) and damageassociated molecular patterns (DAMP). Quercetin works as an antiinflammatory by inhibiting these regulators and, thereby is an NLRP3 inflammasome (Ali Saeedi-Boroujeni et al.,2021). According to Derosa et al. (2020), the major targets for mitigating SARS-CoV2 infection, include papainlike protease (PLpro), spike (S) protein, 3 chymotrypsinlike protease (3CLpro), and RNA dependent RNA polymerase and quercetin inhibits 3CLpro and PLpro.

\subsection{Kaempferol}

Kaempferol (3,5,7-trihydroxy-2-(4-hydroxy-phenyl) chromen-4one) is another flavonoid that can be obtained from several vegetables like cabbage, beans, spinach, kale, tea, broccoli, etc. It is a yellow flavonol largely found in glycosylated or aglycone form (CalderonMontano et al.,2011). It has been observed to be exhibiting antioxidant and anti-inflammatory properties (Zhang et al., 2017). Kaempferol is considered to be effective against cancer and also possesses antiviral activities. This flavanol has the potential to obstruct the $3 \mathrm{a}$ ion channel produced by the ORF3a coded proteins, which leads to reducing viral growth favoring its exit from the host. This property provides the body time gap to enhance its immune system to fight against the virus. Glycoside derivatives of kaempferol exhibited more potent inhibitory action than kaempferol (Sayed et al.,2020). Kaempferol has also exhibited protective action against attenuated pulmonary edema caused by influenza, in mice (Zhang et al., 2017). Yang et al. (2020) reported the antioxidant properties of kaempferol in the lung ischemia-reperfusion injury model showing enhancement of superoxide dismutase and reduction in malondialdehyde.

According to the molecular docking study by Khaerunnisa et al. (2020), kaempferol shows inhibitory activity against viral 
protein active components. Another study by Seri Jo et al. (2019) demonstrated coronavirus 3C-like protease (3CLpro) inhibition by kaempferol. Pharmacological analysis and docking studies by China's national guideline network also put forward the finding that kaempferol could bind with ACE2 receptors along with regulation of T-cell receptors (Chan et al.,2020). Parallel studies by Schwarz et al. (2014) suggested the inhibitory activity of kaempferol glycosides on 3 a channel proteins in coronaviruses.

Hence, it can also be said that kaempferol biding affinity to viruses is comparatively higher amongst the flavonoids and it can be a potent candidate for an anticoronal agent.

\subsection{Resveratrol}

Resveratrol (3,4,5-trihydroxy-trans-stilbene) belongs to class polyphenol found in human-consumed plants like red grapes mulberry and peanuts. It is classified as a phytoalexin and is present in $50-100 \mathrm{mg} / \mathrm{g}$ in sources like Vitis vinifera, the common vine. Resveratrol exhibits many biological activities like antiplatelet, cardioprotective, antioxidant, anticarcinogenic, anti-inflammatory, and immunomodulatory activity. It also induces lymphocyte proliferation, activates natural killer cell cytotoxicity. Further, it regulates the apoptotic mechanism (Gianchecchi et al.,2020). It has been explained by in vitro experiments that resveratrol elicits antiviral activity in animals and human cells against viruses like Varicella zoster (Docherty et al.,2006), Herpes simplex virus (Docherty et al.,1999) polyomavirus (Berardi et al.,2009), HIV and influenza (Palamara et al.,2005). Not only viruses but parasites like Leishmania (Kedzierski et al.,2007) and bacteria like Serratia marcescens (Lu et al.,2008) and Neisseria (Docherty et al.,2001) also are susceptible to resveratrol.

Furthermore, resveratrol also stimulates Nrf2, required for acclimatization of cells under oxygen stress. It is facilitated by reducing the expression of negative regulators like KEAP1, and by activating SIRT1 deacetylase (Ungvari et al.,2010). The active Nrf2 pathway causes dissociation of the Keap1-Nrf2 cytoplasmic complex and migration of Nrf2 to the nuclear compartment which stimulates target genes transcription having promoter sequences for antioxidant response element (Zhang et al., 2012). Further, activated genes protect cells from oxygen stress and aid in suppressive response to inflammation. (Ahmed et al., 2017; Kobayashi et al.,2016). Ghanim et al. (2011) and Kode et al. (2008) supported the claim that the decreased levels of inflammatory cytokines on oral administration of resveratrol as it activates the Nrf2 target gene expression, causing enhanced production of endogenous, glutathione thus protecting epithelial cells of alveoli from excessive oxygen stress. Thus, resveratrol may provide relief by affecting susceptibility to SARS-CoV-2 infection and also severity of infection. The therapeutic action of resveratrol has been elucidated for the novel coronaviruses SARS-CoV-2 (Wahedi et al.,2020) and MERS-CoV (Lin et al.,2017) using in vitro analysis. Resveratrol treatment after 48 hours of infection led to inhibition of MERS CoV-induced apoptosis and viral replication. This is related to the reduced expression of viral nucleocapsid proteins (Lin et al.,2017). A drawback however is with regards to the bioavailability of resveratrol which is low due to low uptake in the GI tract, low solubility, greater affinity towards lipids, rapid breakdown, and elimination through kidney and liver (Wenzel and Somoza, 2005). High-fat content or a high-fat diet results in a lowered uptake of supplemented resveratrol, as proven by Ramírez-Garza et al. (2018). Although, this finding was not in accordance with studies done by Vitaglione et al. (2005).

Studies have demonstrated the inhibitory activity of resveratrol against SARS-CoV in vitro (Yang et al.,2020; Li et al.,2006). Molecular docking studies have revealed powerful interaction between the human ACE2 receptor complex and spike proteins of SARS-CoV-2 (Wahedi et al.,2020), which holds its claim to be a good nutraceutical against COVID-19.

\subsection{Apigenin}

Yet another flavonoid present in parsley, celery, organs, onions, and herbs is apigenin. In vitro analysis of apigenin has demonstrated the activity against DNA and RNA viruses including Herpes Simplex Virus-1, Poliovirus type-2, hepatitis B virus, adenoviruses, and hepatitis C virus (Shimon Ben-Shabat et al., 2019). It has been observed that hydroxylation of apigenin at 3 positions is a mandatory requirement for antiviral activity of the non-glycosidic compound (Tapas et al.,2008). Apigenin has also been reported as an antihyperglycemic (Villa-Rodriguez et al.,2018) antiapoptotic (Zhou et al.,2018) antioxidant, and anti-inflammatory (Fidelis et $a l ., 2019)$. In addition to the above, other health benefits include its activity as cytostatic and cytotoxic agents and antiatherogenic (Fahad Ali et al.,2017). Experiments done by Patrick Moore et al. (2017) suggested the immunomodulatory activity of apigenin on RelB, an NF-kB family protein which in turn cause modulation of dendritic cells.

In silico studies on apigenin 7 glucoside have reported its inhibitory action on SARS-CoV-2 Mpro (Khaerunnisa et al.,2020). Sui et al. (2010) experimented with hypertensive rats' kidneys to check the effect of angiotensin-converting enzyme 2 and it was found that the transcription and expression of the ACE2 gene were positively regulated. In lipopolysaccharide-activated mouse macrophages, apigenin has shown the ability to produce proinflammatory cytokines and anti-inflammatory myokines by inactivating nuclear factor kappa light chain enhancer and by activating B cells which leads to a sharp decrease in IL-6 (Salehi et al., 2019; Sui et al., 2010). Apigenin induces various anti-inflammatory pathways, as it reduces COX-2 activity in humans. It also possesses healing properties which influence metabolic pathway affecting pharmacokinetics and tissue distribution. The therapeutic effect of apigenin has been studied (Liang et al., 2001) proving its therapeutic effects on neuroinflammation. Nielsen et al. (1999) worked on the effect of parsley with high apigenin levels, on the flavone excretion through urine, and on biomarkers for oxidative stress. This twoweek randomized crossover trial demonstrated that a fraction of apigenin excreted in the urine was $0.58 \%$ when the subject was supplemented with 3.73 to $4.49 \mathrm{mg}$ of apigenin. Wei Zhang et al. (2014) estimated EC50 for apigenin to block Enterovirus-71 (EV-71) as $10.3 \mu \mathrm{M}$. In addition to the identification of apigenin as an antiviral agent against EV71 infection, they also exemplified the significance of apigenin as an antiviral agent by targeting host factors essential for replication of the virus. It is found to be an effective antiviral therapy against African Swine Fever Virus (ASFV) by inhibiting ASFV-specific protein synthesis and viral factory formation. In vitro analysis of ASFV-infected cells treated with apigenin did not display a cytopathic effect (Hakobyan et al.,2016). On docking main protease and spike proteins with 75 phyto- 
chemicals, a flavanoid apigenin was observed to be the most potent inhibitor of Mpro rather than spike protein. (Kumar et al., 2020).

\subsection{Carotenoids}

Carotenoids are a class of bioactive compounds showing quenching property towards reactive oxygen species, thereby exhibiting immune modulator activity (Krinsky and Johnson, 2005). They are tetraterpenoids, lipid-soluble plant pigments providing red, orange, and yellow color to vegetables and fruits. Over 750 varieties of carotenoids have been elucidated from natural sources with the vast difference in their physiochemical as well as functional properties (Amengual et al.,2019).

Carotenoids are found to play a major role in cellular differentiation and growth of tissue (Rucker et al.,2008). It is also postulated that carotenoids may increase the activity of NK cells as the immunomodulating property of these components was observed by Jyonouchi et al. (1991) during the action of mitogens on the activity of the spleen. Also, it helps to boost the immune system by the rising cell to cell communication by increasing the exchange of growth regulatory signals which leads to apoptosis in damaged cells. Also, carotenoids were proven to enhance the interchange of growth regulatory signals leading to apoptosis of damaged cells (Astley, 2003). Carotenoids Natrialba sp. M6 obtained from halophilic archaea, in an in vitro study, indicated significantly robust activity against $\mathrm{HCV}$ and $\mathrm{HBV}$. This unique outcome suggested that carotenoid Natrialba sp. M6 can be used as an antiviral agent as an alternative to drugs (Ghada et al., 2020).

Walston et al. (2006) revealed a significant increase in IL-6 in women associated with low levels of lutein or zeaxanthin, alpha and beta carotene, and total carotenoids. Naithani et al. (2008) also showed an antiviral effect of lutein, zeaxanthin, and carotene. Carotenoids such as fucoxanthin and astaxanthin have proved to down-regulate the IL-6, IL-1 $\beta$, and TNF- $\alpha$ expression (Jaswir et al., 2011). Santoyo (2012) extracted carotenoids from $D$. salina and $H$. pluvialis and found them to reduce the activity of HSV-1 ranging from $50-85 \%$. Thus, the use of carotenoids as antiviral agents can be further explored for COVID-19.

\subsection{Probiotics}

It is evident that SARS-CoV and its variant CoV-2 infection depends upon the binding potential of the spike proteins (S) with Angiotensin-Converting Enzyme 2 (ACE2) in human cells (Hoffmann et al.,2020) and is generally expressed in the lungs, esophageal cells, and stratified epithelia, enterocytes from ileum and colon. Zhang et al. (2020) indicated that the digestive system is also a potential route for COVID-19 infection. The protein TMPRSS2 is also found to be responsible for the entry of the viral material into the host cell which is hugely expressed in intestinal enterocytes (Bertram et al.,2012) and watery diarrhea was the most common gastrointestinal symptom noted in these patients. The intestinal studies suggest that viral load in the digestive mucosal layer increases due to the ability of the virus to replicate in the absorbent cells. This could cause loss of integrity of the digestive system along with fluctuation in the microbiota and metabolites (Hashimoto, 2012; Leung et al., 2003)

A mixture of probiotics and prebiotics also known as synbiotics can affect the host cells in a positive sense by improving the survival of live microbial dietary supplements. It could stimulate the growth of intestinal microbiota and activate the metabolism of many healthpromoting microorganisms (Swanson et al.,2020). The metabolic products of gut microorganisms comprising short-chain fatty acids may reach other organs like lungs, adversely influencing respiratory disorders. Schuijt et al. (2016) in a study with Pneumococcal pneumonia revealed that the gut microorganisms contribute to lung immunity as the gut and lung are interconnected, and imbalance in the gut microbiome is highly associated with lung diseases. Disease development may cause the microbial environment to influence and provide resistance to colonization of respiratory pathogens. The bacterial metabolites can activate macrophages in alveolar cells through activated B cells and elicit a cellular response through the action of Toll-like receptor link, providing lung immunity functions (McAleer et al.,2018). Studies suggest the role of probiotics in immune modulation of binnate functions possibly due to the introduction of natural killer lymphocytic cells (Belkacem et $a l ., 2017)$. In a pilot study on children with cystic fibrosis, Weiss $e t$ al. (2010), suggested that the supplementation of probiotics, specifically Lactobacillus GG, reduced pulmonary aggravations rate. The native sinus ecology can be restored by the use of probiotics with significant therapeutic and preventive implications (Giudice $e t$ al.,2020). Ichinohe et al. (2011) suggested that the intestinal microflora can stimulate the generation of pro-inflammatory cytokines, like IL-18 and IL-1 which in turn activate the innate immune response in respiratory viruses like the influenza virus. This leads to up-regulation of the expression of costimulatory substances on dendritic cells. Panigrahi et al. (2017) conducted an experiment on newborns in India suffering from sepsis and lower RTI and found a reduction in an infection on treatment with Lactobacillus plantarum combined with prebiotics. Random 479 adults were screened, double-blinded, by de Vrese et al. (2005) for the common cold and several probiotics proved that Bifidobacterium bifidum MF 20/5, Bifidobacterium longum SP 07/ 3 , and Lactobacillus gasseri PA 16/8, in addition to minerals and vitamins lowered the duration of cold conditions. A 1:1 mixture of polydextrose and galacto-oligosaccharide or Lactobacillus rhamnosus GG, when provided for an average of 2 months leads to a lowered incidence of virus-associated RTI (Luoto et al., 2014). Furthermore, the upper respiratory tract microbiota in healthy people also comprising of lactic acid bacteria, and some strains have been considered for inhibition of recurring otitis media (Rautava et al.,2009; Cardenas et al.,2019). It is evident that supplementation of lactobacilli or bifidobacteria has a favorable influence on the clearance of the influenza virus from the respiratory tract (Zelaya et al.,2016). Strasser et al. (2016) reported that various strains of probiotics, including Enterococcus faecium W54, Bifidobacterium bifidum W23, Bifidobacterium lactis W51, Lactobacillus brevis W63, Lactobacillus acidophilus W22 and Lactococcus lactisW58 assisted in reducing the emergence of URTIs in athletes, without affecting the performance.

According to Namba et al. (2010), probiotic strains improve levels of type I interferons along with increasing the number as well as activity of APCs, natural killer cells, T cells along with the levels of mucosal specific antibodies related to lungs. It has been proven that orally taken probiotics have the potential to reduce the occurrence and severity of viral respiratory tract infections (Baud $e t$ $a l ., 2020)$. These findings would be able to relate the use of probiotics as an antiviral therapy to improve respiratory activities during infection. During the COVID-19 pandemic, the application 
of probiotic treatment was recommended by the National Administration of Traditional Chinese Medicine and the Chinese National Health Commission to combat the infection. Dumas et al. (2018) observed a two-directional relationship, the gut-lung axis between the gut and lungs microflora, in which gut microbiota metabolites have an impact on the lungs via the circulatory system and the lung microorganisms may influence the gut microflora. Hence, it can be postulated that the gut-lung axis would play important role in prospects of the pathogenesis of COVID-19 and a potential target for treatments.

\section{Conclusion}

The above-mentioned nutraceuticals are prospective candidates for prevention, management, and therapy of COVID-19. Nutraceuticals basically possess medicinal properties as they are rich in phytochemicals which have been known to possess pleiotropic activities. Nutraceutical mediates the boosting of the immune response in an individual and works largely as immunomodulators thereby leading our defense system by: (i) countering pathogens and their associated injuries, (ii) preventing/controlling anomalous immune responses like the ones occurring during autoimmune diseases or in case of SARS-CoV-2 by-passing of innate immune response, (iii) acting as immune-stimulators to enhance the mediators of the immune system. Such approaches (Figure 3) lead to a possible remedy for viral infections by not only preventing attachment and penetration of the virus into the host cell but also mitigating the symptoms and reducing the severity as well as the duration of the disease.

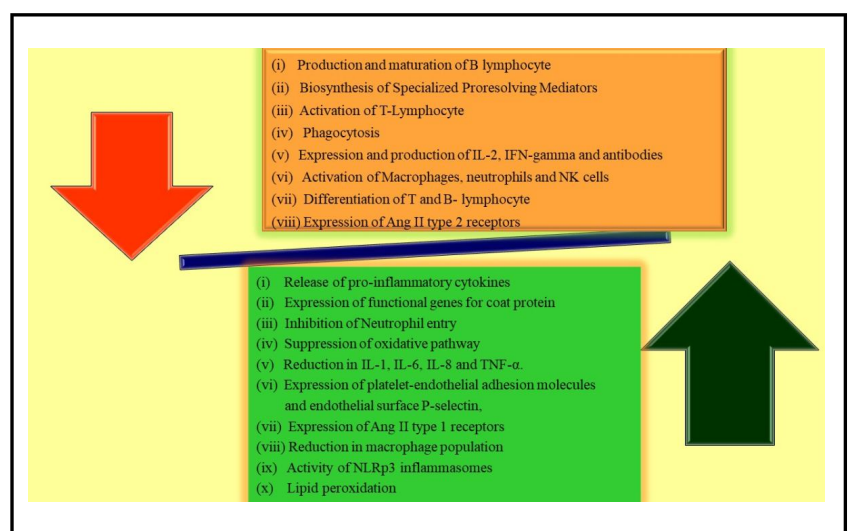

Figure 3: Immunomodulatory effects of nutraceuticals.

Among the nutraceuticals discussed, most act as both immunomodulators as well as mitigate the viral entry in host cells. The nutraceuticals have a humongous benefit of being well-tolerated with hardly any reports of adverse reactions.

Table 1: Summary of nutraceuticals and the mode antiviral action.

\begin{tabular}{|c|c|c|c|c|}
\hline Nutraceuticals & Schematic representation & & Mode of action against viruses & References \\
\hline $\begin{array}{l}\text { Polyunsaturated } \\
\text { fatty acids }\end{array}$ & 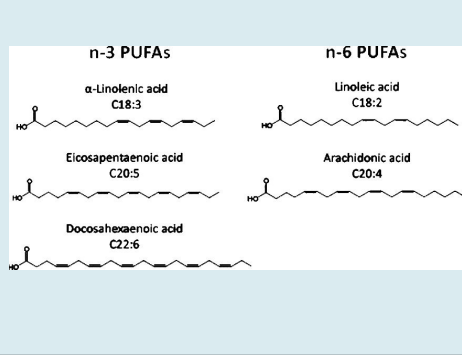 & $\begin{array}{l}\text { (i) } \\
\text { (ii) } \\
\text { (iii) }\end{array}$ & $\begin{array}{l}\text { DHA and EPA act as anti-infla- } \\
\text { mmatory in the macrophages } \\
\text { of asthmatic alveoli. } \\
\text { Production of endogenous SPM } \\
\text { like protectins and mediators } \\
\text { Prophylactic, therapeutic } \\
\text { anticoagulants and antithrombotic } \\
\text { in nature }\end{array}$ & $\begin{array}{l}\text { Mickleborough et al. (2009); } \\
\text { Buckley et al. (2014); } \\
\text { Tsoupras et al. (2020); } \\
\text { Bikdeli et al. (2020) }\end{array}$ \\
\hline Arginine & & $\begin{array}{l}\text { (i) } \\
\text { (ii) }\end{array}$ & $\begin{array}{l}\text { Effective in pore formation, } \\
\text { destabilization of the membrane, the } \\
\text { inhibition of non-structural protein } \\
\text { functions and inhibition of inter } \\
\text { protein. } \\
\text { Reduction in lungs airway inflamm- } \\
\text { ation }\end{array}$ & $\begin{array}{l}\text { Tsuji moto et al. (2010); } \\
\text { Yamasaki et al. (2008); } \\
\text { Meingast and Heldt } \\
\text { et al. (2020); } \\
\text { Zhang et al. (2015) }\end{array}$ \\
\hline Glutamine & $\mathrm{NH}_{2}$ & $\begin{array}{l}\text { (i) } \\
\text { (ii) } \\
\text { (iii) }\end{array}$ & $\begin{array}{l}\text { Immunosuppressive and anti- } \\
\text { inflammatory } \\
\text { Reduction of lungs edema, } \\
\text { inhibition of cytokine production } \\
\text { and prevention of neutrophil entry } \\
\text { into lungs. } \\
\text { Effective agent against acute } \\
\text { respiratory distressed syndrome } \\
\text { and lung cancer }\end{array}$ & $\begin{array}{l}\text { Pierre et al. (2013); } \\
\text { Lai et al. (2014); } \\
\text { Oliveira et al. (2016) }\end{array}$ \\
\hline Glucan & $9 / 80^{\circ}$ & (i) & $\begin{array}{l}\text { Anti-inflammatory response and } \\
\text { Inhibitor of ARDS. } \\
\text { Inducer of macrophages, neutrophils, } \\
\text { and NK cells exhibiting defense } \\
\text { against respiratory tract infection. }\end{array}$ & $\begin{array}{l}\text { De Marco et al. (2020); } \\
\text { Urbancikova et al. (2020); }\end{array}$ \\
\hline
\end{tabular}




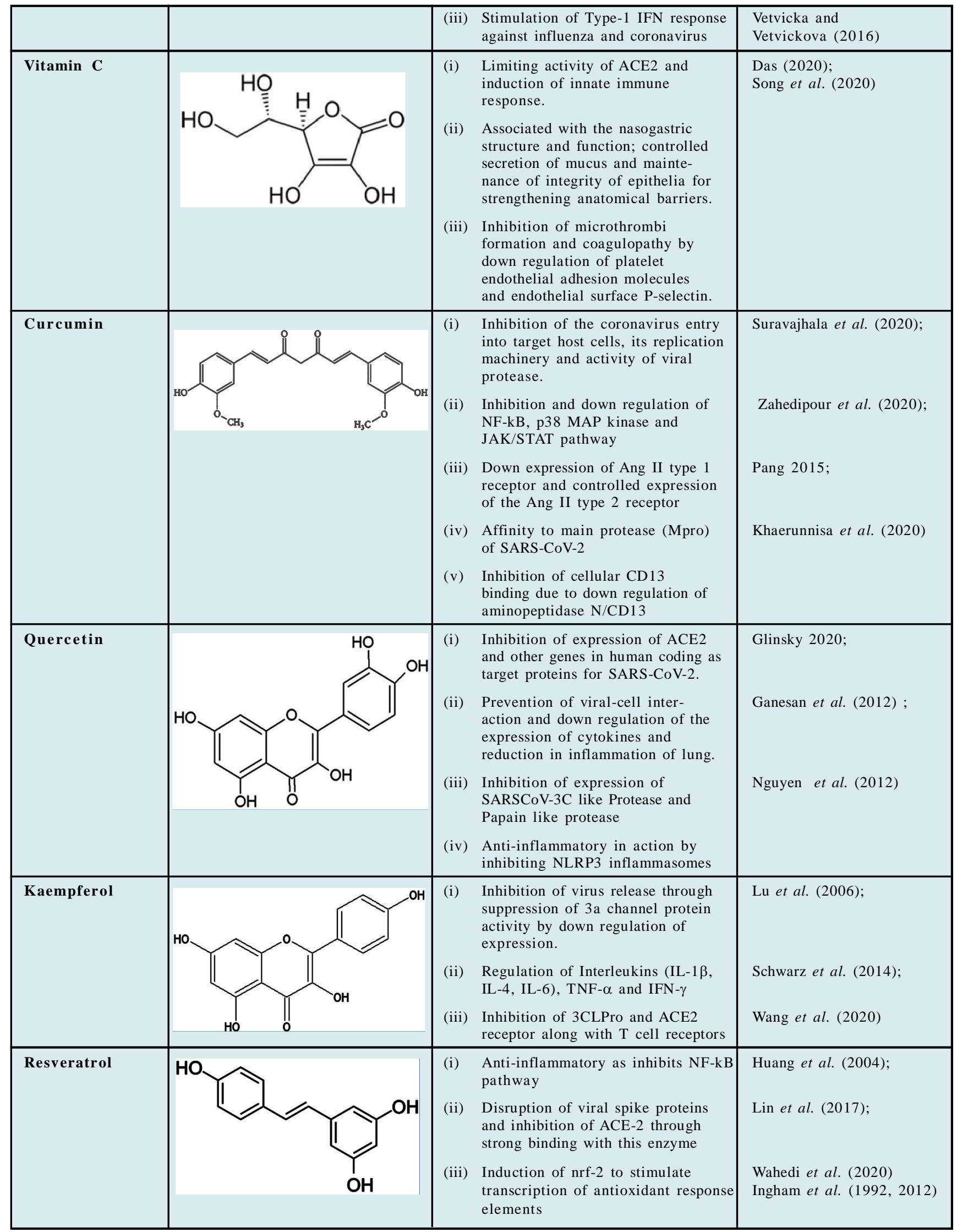




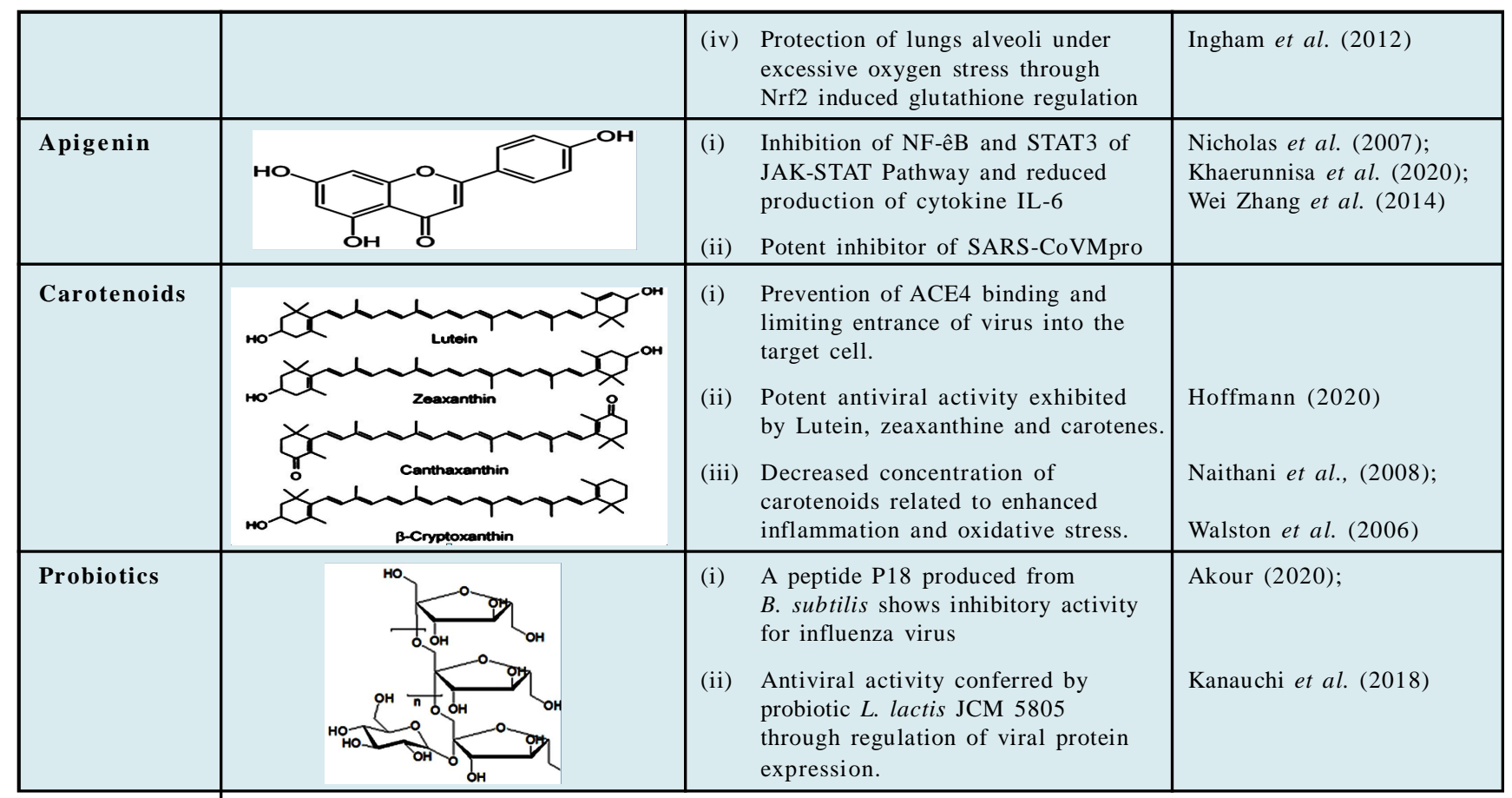

The symptoms of SARS-CoV-2 infection are those similar to common flu initially. The host for the virus is the ACE receptor found in cells of the respiratory system and, hence the severity of infection leads to ARDS which further leads to the affect seen on all systems of the body, ultimately leading to multi organ failure. To curb the infection early, a viable option can be the use of immunomodulatory nutraceuticals evidenced to work on strengthening the immune system. In the present review a few nutraceuticals are considered and Table 1, summarizes their antiviral properties.

Researchers across the globe are currently working towards providing validity to the pharmacological benefits of nutraceuticals, especially in refence to the current pandemic and more such investigations will help strengthen their authenticity towards the capacity to modulate the immune system and see the end of the pandemic.

\section{Acknowledgements}

Financial and infrastructural support to the Department of Biochemistry from Shri Vile Parle Kelavani Mandal (SVKM) and Mithibai College (Autonomous) is gratefully acknowledged.

\section{Conflict of interest}

The authors declare that there are no conflicts of interest relevant to this article.

\section{References}

Ahmed, S.M.; Luo, L.; Namani,A.; Wang, X.J. and Tang, X., (2017). Nrf2 signaling pathway: Pivotal roles in inflammation. Biochim. Biophys. Acta Mol. Basis Dis., 1863:585-597.

Akramiene, D., (2007). Effects of beta-glucans on the immune system. Medicina (Kaunas, Lithuania) https://doi.org/10.3390/medicina 43080076 .
Akour A. (2020). Probiotics and COVID 19: Is there any link? Review article, letters in applied microbiology ISSN 0266-8254, doi: $10.1111 /$ lam.13334.

Tsoupras, A.; Ronan Lordan and Ioannis Zabetakis, (2020). Thrombosis and COVID-19 : The potential role of nutrit. Front. Nutri., 9(25):DOI: $10.3389 /$ fnut. 2020.583080

Ali Saeedi-Boroujeniand, Mohammad-Reza and Mahmoudian-Sani. (2021). Anti-inflammatory potential of Quercetin in COVID-19 treatment; Journal of Inflammation. 18:23-31.

Amarin Corporation and HLS Therapeutics, Inc, (2020). An investigation on the effects of icosapent ethyl (VascepaTM) on inflammatory biomarkers in individuals with COVID-19: Full text view - clinical trials. gov https://clinicaltrials.gov/ct2/show/NCT04412018.

Amengual, J. (2019). Bioactive properties of carotenoids in human health. Nutrients, 11(10):2388-98.

Anitra, C.; Carr, and Sam Rowe, (2020). The emerging role of vitamin C in the prevention and treatment of COVID-19.

Arvinte, Cristian.; Singh, R. and Marik, P.E. (2020). Serum levels of Vitamin C and Vitamin D in a cohort of critically III COVID-19. Patients of a North American Community Hospital Intensive Care Unit in May 2020: A Pilot Study Medicine. Drug Discovery, 12:DOI:10.1016/ j.medidd.2020.100064 .

Astley, S.B. (2003). Antioxidants role of antioxidant nutrients, in defense Systems, Encyclopedia of Food Sciences and Nutrition, 2nd edn , Academic Press, New York, pp:282-289.

Avasarala, S.; Zhang, F.; Liu, G.; Wang, R.; London, S. D. and London, L. (2013). Curcumin modulates the inflammatory response and inhibits subsequent fibrosis in a mouse model of viral-induced acute respiratory distress syndrome. Phytotherapy Research. PloS One, $8(2):$ e57285. infection.

Bachmetov, L.; Gal-Tanamy, M.; Shapira, A.; Vorobeychik, M.; GitermanGalam, T.; Sathiyamoorthy, P.; Golan-Goldhirsh, A.; Benhar, I.; Tur Kaspa, R.; Zemel, R., (2012). Suppression of hepatitis $C$ virus by the flavonoid quercetin is mediated by inhibition of NS3 protease activity. Journal of Viral Hepatitis, 19(2):81-88. 
Baud, D.; Agri, V.D.; Gibson, G.R.; Reid, G. and Giannoni, E. (2020). Using probiotics to flatten the curve of coronavirus disease COVID-19 pandemic, frontiers in public health-infectious Disease-Surveillance, Prevention and Treatment, doi.org/10.3389/fpubh.2020.00186.

Bedoya, L. M.; Beltrán, M.; Obregón-Calderón, P.; García-Pérez, J.; de la Torre, H. E.; González, N.; Pérez-Olmeda, M.; Auñón, D.; Capa, L.; Gómez-Acebo, E. and Alcamí, J. (2016). Hydroxytyrosol: A new class of microbicide displaying broad anti-HIV-1 activity. AIDS, 30(18):2767-2776.

Beigel J.H.;Tomashek K. M.; Lori E. D.; MehtaAK.;Zingman B S.;Kalil A.;Hohmann E.;Chu H Y.;LuetkemeyerA.; Kline S.; de Castilla D.L. and Finberg R.W. (2020). Remdesivir for the treatment of COVID-19: Final report, the New England Journal of Medicine, 383:1813-1826, DOI: 10.1056/ NEJMoa2007764.

Berardi, V.; Ricci, F.; Castelli, M.; Galati, G. and Risuleo, G. (2009). Resveratro exhibits a strong cytotoxic activity in cultured cells and has an antiviral action against polyomavirus: Potential clinical use. J. Exp. Clin. Cancer Res., 28:96-111.

Bertram, S.; Heurich, A.; Lavender, H.; Gierer, S.; Danisch, S.; Perin, P.; Lucas, J.M.; Nelson, P.S.; Pöhlmann, S. and Soilleux, E.J. (2019). Influenza and SARScoronavirus activating proteases TMPRSS2 and HAT are expressed at multiple sites in human respiratory and gastrointestinal tracts. PLoS ONE2012,7, e35876.

Bhatia, S.; Giri, S.; Lal, A.F. and Singh, S. (2020). Battle against coronavirus: Repurposing old friends (food borne polyphenols) for new enemy (COVID-19), Chem. R. xiv, Preprint.

Bikdeli, B.; Madhavan, M.V.; Jimenez, D.; Chuich, T.; Dreyfus, I.; Driggin, I.; Nigoghossian, C.D.; Ageno, W.A.; Madjid, M. and Lip, Y.H. (2020). COVID19 and thrombotic or thromboembolic disease: Implications for prevention, antithrombotic therapy, and follow-up. Jour. Amer. Coll. Cardio., (06):DOI: 10.1016/j.jacc.2020.04.031.

Boretti, A. and Banik, B.K. (2020). Intravenous vitamin C for reduction of cytokines storm in acute respiratory distress syndrome. Pharma. Nutrition, 100190:110-119.

Butorov, E.V., (2015). Influence of L-lysine amino acid on the HIV-1 RNA replication in vitro. Antivir. Chem. Chemother., 24(1):39-46.

Cai, Y.; Li, Y. F.; Tang, L. P.; Tsoi, B.; Chen, M.; Chen, H.; Xiao-Mei Chen.; Rui-Rong Tan; Hiroshi Kurihara and Rong-Rong He. (2015). A new mechanism of vitamin $\mathrm{C}$ effects on $\mathrm{A} / \mathrm{FM} / 1 / 47$ (H1N1) virus-induced pneumonia in restraintstressed mice. Bio. Med. Res. Int.,2015:https://doi.org/ $10.1155 / 2015 / 675149$

Calder, P. C.; Carr, A. C.; Gombart, A. F. and Eggersdorfer, M. (2020). Optimal nutritional status for a well-functioning immune system is an important factor to protect against viral infections. Nutrients, 12(4): 1181-91.

Calderon-Montano M. J.; Burgos-Morón, E.;Pérez-Guerrero, C. and López-Lázaro, M. (2011). A review on the dietary flavonoid kaempferol. Mini. Rev. Med. Chem. 11:298-344.

Calvo A.V.; Oya N.J.; Martín-Acebes M.A.; Moruno E.G. and Saiz, J.C. (2017) Antiviral properties of the natural polyphenols delphinidin and epigallocatechin gallate against the Flaviviruses West Nile Virus, Zika Virus, and Dengue Virus, Front. Microbiol., Front Microbiol; 8:1314. doi: 10.3389/fmicb.2017.01314. eCollection.

Carcaterra, M. and Caruso, C. (2020). Alveolar epithelial cell type II as main target of SARS-CoV-2 virus and COVID-19 development via $\mathrm{NF}-\mathrm{Kb}$ pathway deregulation: A physiopathological theory. Med. Hypotheses, pp:110412.

Cardenas, N. and Martin, V.; Arroyo, R.; López, M.; Carrera, M. and Badiola, C. (2019). Prevention of recurrent acute otitis media in children through the use of Lactobacillus salivarius PS7, a target-specific probiotic strain. Nutrients, 11:doi:10.3390/nu11020376.
Carita, A.C.; Fonseca-Santos, B.; Shultzand J.D.; Michniak-Kohn, B.; Chorilli, M. and Leonardi, G.R. (2020). Vitamin C: One compound, several uses. Advances for delivery, efficiency and stability. Nanomedicine, 24: 102-117.

Carr, E.L.; Kelman, A.; Wu, G.S.; Gopaul, R.; Senkevitch, E.; Aghvanyan, A.; Turay, A.M.; Frauwirth, and K.A. (2010). Glutamine uptake and metabolism are coordinately regulated by ERK/MAPK during $\mathrm{T}$ lymphocyte activation. J. Immunol., 185:1037-1044.

Carrasco-Castilla, J.; Hernández-Álvarez, A.; J., Jiménez-Martínez, C.; JacintoHernández, C.; Alaiz, M.; Girón-Calle, J.; Vioque, and J. and Dávila-Ortiz G. (2012). Antioxidant and metal chelating activities of pep-tide fractions from phaseolin and bean protein hydrolysates. Food Chemistry, 135(3): 1789-1795.

Cecchini, R. and Cecchini, A.L. (2020). SARS-CoV-2 infection pathogenesis is related to oxidative stress as a response to aggression. Med. Laforge Hypotheses, 143:110102.

Chan, K.W.; Wong, V.T. and Tang, S.C.W. (2020). COVID-19 : An update on the epidemiological, clinical, preventive and therapeutic evidence and guidelines of integrative Chinese-Western medicine for the management of 2019 novel coronavirus disease. Am. J. Chin. Med., 48:737-762.

Chanda, Silpi; Tiwari, R.K.; Kumar, A. and Singh, Kuldeep.(2019). Nutraceuticals inspiring the current therapy for lifestyle diseases. Ad. Pharma. Sc.: https://doi.org/10.1155/2019/6908716.

Chen, G.; Wu, D.; Guo, W.; Cao, Y.; Huang, D.; Wang, H.; Wang, T.; Zhang, X. and Chen, H., Yu, H., (2020). Clinical and immunological features of severe and moderate coronavirus disease 2019. J. Clin. Investig., 130: 2620-2629.

Chen, H.S.; Wang, S.; Zhao, Y.; Luo,T.; Tong, H.S. and Lei Su (2018). Correlation analysis of omega-3 fatty acids and mortality of sepsis and sepsis induced ARDS in adults: Data from previous randomized controlled trials. Nut. Jour. 05(31):DOI:10.1186/s12937-018-0356-8.

Cheng, Z; Yu, T.; Xia, J.; Wei, Y.; Wu, W.; Xie, X.; Yin, W.; Li, H.; Liu, M. and Xiao, Y. (2020). Breadth of concomitant immune responses prior to patient recovery: A case report of non-severe COVID-19. Nat. Med., 26(4), 453-455, https://doi.org/10.1038/s41591-020-0819-2.

Christopher D.; Buckley, D.; Gilroy,W. and Serhan, C.N. (2014). Proresolving lipid mediators and mechanisms in the resolution of acute inflammation. Immunity (03):DOI: 10.1016/j.immuni.2014.02.009.

Corti, A.; Casini, A.F. and Pompella, A. (2010). Cellular pathways for transport and efflux of ascorbate and dehydroascorbate. Arch. Biochem. Biophys., 500:107-115.

Das, U.N. (2019). Polyunsaturated fatty acids and sepsis. Nutrition, 09: https://doi.org/ghvqnb DOI: 10.1016/j.nut.2019.02.016.PMID: 31029920

De Marco Castro, E.; Calder, P.C. and Roche, H.M. (2020). $\beta 1,3 / 1,6$ glucans and immunity: State of the art and future directions. Mol. Nutr. Food Res.,e1901071:doi:10.1002/mnfr.201901071.

Derosa, G.; Maffioli, P.; D'Angelo, A. and DiPierro F. (2020). A role for quercetin in coronavirus disease (COVID 19), Phytother. Res.,:10.1002/ ptr.6887.doi: $10.1002 /$ ptr.6887.

De Oliveira, C. F.; Corrêa, A. P.; Coletto, D.; Daroit, D. J. and Cladera-Olivera, F.; Brandelli, A. (2015). Soy protein hydrolysis with microbial prote-ase to improve antioxidant and functional properties. Jour. Food Sc. Tech., 52(5):2668-2678.

De Vrese, M.; Winkler, P.; Rautenberg, P.; Harder, T.; Noah, C. and Laue, C., (2009). Effect of Lactobacillus gasseri PA 16/8, Bifidobacterium longum SP $07 / 3$, B. bifidum MF $20 / 5$ on common cold episodes: a double blind, randomized, controlled trial. Clin. Nutr., 24:481-491. 
Calderon, A.G.; Maffioli, P.; D’Angelo, A. and Di Pierro, F. (2020). A role for quercetin in coronavirus disease 2019 (COVID-19); Phytotherapy Research: https://doi.org/10.1002/ptr.6887

Dharsono, T.; Rudnicka, K.; Wilhelm, M. and Schoen, C. (2019). Effects of yeast $(1,3)(1,6)$ beta glucan on severity of upper respiratory tract infections: A double blind, randomized, placebo controlled study in healthy subjects. J. Am. Coll. Nutr., 38:40-50.

Dimopoulou, A.V.; Gibson, G.R.; Reid, G. and Giannoni, E., (2020). Using probiotics to flatten the curve of coronavirus disease COVID-2019 Pandemic. Front. Pub. Health, 8:186.

Docherty, J.J.; Fu, M.M.; Stiffler, B.S.; Limperos, R.J.; Pokabla, C.M. and DeLucia, A.L. (1999). Resveratrol inhibition of herpes simplex virus replication. Antiviral Res., 43:145-155.

Docherty, J.J.; Fu, M.M. and Tsai, M. (2001). Resveratrol selectively inhibits Neisseria gonorrhoeae and Neisseria meningitidis. J. Antimicrob. Chemother., 47:243-244

Docherty, J.J.; Sweet, T.J.; Bailey, E.; Faith, S.A. and Booth, T. (2006). Resveratro inhibition of varicella-zoster virus replication in vitro. Antiviral Res., 72:171-177.

Dumas A.; Bernard L.; PoquetY.;Villarino G. L. and Neyrolles O. (2018). The role of the lung microbiota and the gut-lung axis in respiratory infectious diseases, Cell Microbiol., 20(12):e12966. doi:10.1111/cmi.12966.

Ehrlich, S.D. (2009). Peppermint (Mentha Piperita), Private Practice Specializing in Complementary and Alternative Medicine, Review, Veri. Med. Healthcare Network, Phoenix, AZ, USA, 2009.

Ekta K. Kalra (2003). Nutraceutical-definition and introduction. AAPS Pharm. Sci., 5(3):DOI:10.1208/ps050325.

Fadus, M. C., Lau, C., Bikhchandani, J. and Lynch, H.T. (2017). Curcumin: An age-old anti-inflammatory and anti-neoplastic agent. Journal of Traditional and Complementary Medicine, 7(3):339-346.

Fahad, Ali.; Rahul, Falaq.; Naz, Smita Jyoti . and Yasir Hasan Siddique, (2017) Health functionality of apigenin: A review. Int. Jour. Food Properties, 20(6):1197-1238

Fan, D.; Zhou, X.; Zhao, C.; Chen, H.; Zhao, Y. and Gong X. (2011). Antiinflammatory, antiviral and quantitative study of quercetin-3-O- $\beta$ D-glucuronide in Polygonum perfoliatum L, Fitoterapia, 2(6):80510.doi:10.1016/j.fitote.2011.04.007.

Fidelis, Q.C.; Faraone, I.; Russo, D.; AragãoCatunda-Jr, F.E.; Vignola, L.; de Carvalho, M.G.; de Tommasi, N. and Milella, L. (2019). Chemical and Biological insights of Ouratea hexasperma (A. St.-Hil.) Baill.: A source of bioactive compounds with multifunctional properties. Nat. Prod. Res., 33(10):1500-1503.

Foong, L.C.; Imam, M.U. and Ismail, M. (2015). Iron-binding capacity of defatted rice bran hydrolysate and bioavailability of iron in Caco2 Cells. Jour. Agri. Food Chem., 63(41):9029-9036.

Francesco, P. (2020). Tocilizumab in COVID-19 Pneumonia (TOCIVID-19)Full text view- Clinical Trials. gov. https://clinicaltrials.gov/ct2/ show/NCT04317092.

Franz, S.; Rammelt, S.; Scharnweber, D. and Simon, J.C.(2011). Immune response to implants: A review of the implications for the design of immunomodulatory. biomaterials. Biomaterials, 32(28):6692-6709.

Ganesan, S.; Faris, A.N. and Comstock, A.T. (2012). Quercetin inhibits rhinovirus replication in vitro and in vivo. Antiviral Res., 94(3):258271.doi:10.1016/j.antiviral.2012.03.005.

Gao, H.; Guo, L.; Xie, J.; Wang, G.; Jiang, R.; Gao, Z.; Jin, Q.; Wang, J. and Cao, B. (2020). Clinical features of patients infected with 2019 novel coronavirus in Wuhan, China. Lancet, 395(10223):497-506.
Geller, A. and Yan, J. (2020) Could the induction of trained immunity by $\beta$ Glucan serve as a defense against COVID-19. Front. Immunol., 11: 1782-1798.

Geraets, L.; Moonen, H. J.; Brauers, K.; Wouters, E. F.; Bast, A. and Hageman, G. J. (2007). Dietary flavones and flavonoles are inhibitors of poly (ADP ribose)polymerase 1 in pulmonary epithelial cells. The Journal of Nutrition, 137(10):2190-2195.

Ghada E.; Hegazy, MarwaM. ;Abu-Serie; Gehan M.; Abo-Elela; Hanan Ghozlan; Soraya A. Sabry; Nadia A.; Soliman; Yasser, R. and Abdel Fattah (2020). In vitro dual (anticancer and antiviral) activity of the carotenoids produced by haloalkaliphilic archaeon Natrialba sp. M6; Scientific reports., Article Number, pp:59-86

Ghanim, H.; Sia, C.L.; Korzeniewski, K.; Lohano, T.; Abuaysheh, S.; Marumganti, A.; Chaudhuri, A. and Dandona, P.A. (2011). Resveratrol and polyphenol preparation suppresses oxidative and inflammatory stress response to a high-fat, high-carbohydrate meal. J. Clin. Endocrinol. Metab., 96: $1409-1414$

Gianchecchi, E. and Fierabracci, A. (2020). Insights on the effects of resveratrol and some of its derivatives in cancer and autoimmunity: A molecule with a dual activity. Antioxidants, 9:91-99.

Giudice Michele Miraglia D.; Parisi, F.; Indolfi , .; Manti, S.; Leonardi, S.; Decimo, F. and Ciprandi, G. (2020). Nasal microbiome in chronic rhinosinusitis. Minerva Pediatrica, Jul-29, DOI:10.23736/S0026-4946.20.05850-8.

Glinsky, G.V. (2020). Tripartite combination of candidate pandemic mitigation agents: Vitamin D, quercetin, and estradiol manifest properties of medicinal agents for targeted mitigation of the COVID19 pandemic defined by genomics-guided tracing of SARS-CoV-2 targets in human cells. Biomedicines, 8(5):129.doi:10.3390/ biomedicines 8050129 .

Guan, Y.; Zheng, B. J.; He, Y. Q.; Liu, X. L.; Zhuang, Z. X.; Cheung, C. L. and Guan, Y. J. (2003). Isolation and characterization of viruses related to the SARS coronavirus from animals in Southern China. Science, 302: 276-278.

Guglielmetti, Gabriele.; Quaglia, M.; Pier Paolo Sainaghi.; Mario Castello, L.; Vaschetto, R.; Pirisi, M.; Francesco Della Corte.; Gian Carlo Avanzi.; Piero Stratta. and Vincenzo, C. (2020). "War to the knife" against thrombo inflammation to protect endothelial function of COVID-19 patients. Critical Care, 06(19):DOI:10.1186/s13054-020-03060-9.

Hakobyan, Astghik.; Arabyan, E.; Avetisyan, A.; Abroyan, L.; Hakobyan, L. and Hovakim Zakaryan, (2016). Apigenin inhibits African swine fever virus infection in vitro. Archives of Virology, 161:3445-3453.

Harri Hemilä and Elizabeth Chalker (2019). Vitamin C can shorten the length of stay in the ICU: A Meta-Analysis.

Hashimoto, T.; Perlot, T.; Rehman, A.; Trichereau, J.; Ishiguro, H.; Paolino, M.; Sigl, V.; Hanada, T.; Hanada, R. and Lipinski, S. (2012). ACE2 links amino acid malnutrition to microbial ecology and intestinal inflammatio. Nature, 487:477-481.

Hemil"a, H. and Suonsyrj, A.T. (2017). Vitamin C for preventing atrial fibrillation in high risk patients: A systematic review and metaanalysis. BMC Cardiovascular Disorders, 17(1):49-61.

Hiedra, R.; Bryan Lo, K.; Mohammad, E.; Fahad, G.; Matthew Wright, R.; Albano, J.; Azmaiparashvili, Z. and Gabriel Patarroyo Aponte (2020). The use of IV vitamin C for patients with COVID-19: A case series expert review of anti-infective. Therapy, 08(01): DOI: 10.1080/14787210.2020. 1794819.

Hoffmann, M.; Kleine-Weber, H.; Schroeder, S.; Krüger, N.; Herrler, T.; Erichsen, S.; Schiergens, T.S.; Herrler, G;Wu, N.H. and Nitsche, A. (2020). SARS-CoV-2 cell entry depends on ACE2 and TMPRSS 2 and is blocked by a clinically proven protease inhibitor. Cell, 181(2):271-280. 
Hong Kong Centre for Health Protection (2020). Countries/areas with reported cases of novel. https://www.chp.gov.hk/files/pdf/statistics_of_the_ cases_novel_coronavirus_infection_en.pdf

Huang, M.T.; Ghai, G. and Ho, C.T. (2004). Inflammatory process and molecular targets for anti-inflammatory nutraceuticals. Compr. Rev. Food Sci. Food Saf., 3(1):127-139.

Husson, M.O.; Ley, D.; Portal, C.; Gottrand, M. and Hueso, T. (2016). Modulation of host defence against bacterial and viral infections by omega-3 polyunsaturated fatty acids. Jour. Infect., 12:DOI:10.1016/ j.jinf.2016.10.001.

Ichinohe, T.; Pang, I.K.; Kumamoto, Y.; Peaper, D.R.; Ho, J.H. and Murray, T.S. (2011). Microbiota regulates immune defense against respiratory tract influenza A virus infection. Proc. Natl. Acad. Sci. USA.108:5354-5359.

Ikeda, K.; Yamasaki, H.; Minami, S.; Suzuki, Y.; Tsujimoto, K.; Sekino, Y.; Irie, H.; Arakawa, T. and Koyama, A.H. (2012). Arginine inactivates human herpesvirus 2 and inhibits genital herpesvirus infection. Int. J. Mol. Med., 30:1307-1312.

Ikeda, K.; Yamasaki, H.; Minami, S.; Suzuki, Y.; Tsujimoto, K.; Sekino, Y.; Irie, H.; Arakawa, T. and Koyama, A.H. (2010). Novel strategy with acidic arginine solution for the treatment of influenza A virus infection. Exp. Ther. Med., 1:251-256.

Ingham, R. (2019). The optional subject phenomenon in young children's English: A case study. J. Child. Lang., 19:133-151. J. Med., doi: 10.1056/NEJMoa2007764.

Jamwal, R. (2018). Bioavailable curcumin formulations: A review of pharmacokinetic studies in healthy volunteers. Jour. Integrative Med., 16(6):367-374.

Jaswir,I.; Monsur, H.A. (2011). Anti-inflammatory compounds of macro algae origin: A review. J. Med. Plants Res. Acad., 5(33):7146-7154.

Jo, S.; Kim, S.; Shin, D.H. and Kim, M.S. (2020). Inhibition of SARS-CoV 3CL protease by flavonoids. J. Enzym. Inhib. Med. Chem., 35:145-151

Johari, J.; Kianmehr, A.; Mustafa, M.R.; Abubakar, S. and Zandi, K. (2012) Antiviral activity of baicalein and quercetin against the Japanese encephalitis virus. International Journal of Molecular Sciences, 13(12):16785-16795.

José, R.J.; Williams, A.; Manuel, A.; Brown, J.S. and Chambers, R.C. (2020) Targeting coagulation activation in severe COVID-19 pneumonia: Lessons from bacterial pneumonia and sepsis. Eur. Resp. Rev., 10 (01).DOI: 10.1183/16000617.0240-2020

Joseph, M.; Khan, Shaheer; Badeaux, Mark; Rao, R.M.; Rowlinso, S.W. and Carvajal, R. (2021). Arginine depletion as a therapeutic approach for patients with COVID-19. Int. Jour. of Inf. Dis., 102:566-570.

Jyonouchi, H.; Hill, R.J.Y. and Tomita, R.A. (1991). Good, studies of immunomodulating actions of carotenoids. I. Effects of $\beta$-carotene and astaxanthin on murine lymphocyte functions and cell surface marker expression in vitro culture system. Nutr. Cancer, 16(2):3105

Kanauchi, O; Andoh, A.; AbuBakar, S. and Yamamoto, N. (2018). Probiotics and paraprobiotics in viral infection: Clinical application and effects on the innate and acquired immune systems, current pharmaceutical design. Bentham Science Publishers, 24(6):710-717.

Kandasamy, M. (2021). NF-kappaBsignalling as a pharmacological target in COVID-19: Potential roles for IKKbeta inhibitors. Naunyn Schmiedebergs Arch. Pharmacol., 394:561-567

Kedzierski,L.; Curtis, J.M.; Kaminska, M.; Jodynis-Liebert,J. and Murias, M. (2007) In vitro antileishmanial activity of resveratrol and its hydroxylated analogues against Leishmania major promastigotes and amastigotes. Parasitol. Res., 102:91-97.
Khaerunnisa, S.; Kurniawan, H.; Awaluddin, R.; Suhartati, S. and Soetjipto, S. (2020). Potential Inhibitor of COVID-19 Main Protease (Mpro) From Several Medicinal Plant Compounds by Molecular Docking Study. Preprints., doi: 10.20944/preprints202003.0226.v1

Khalifa, I.; Zhu, W.; Nafie, M.S. and Dutta, K.; Li, C. (2020). Anti-COVID-19 effects of ten structurally different hydrolysable tannins through binding with the catalytic-closed sites of COVID-19 main protease: An in silico Approach. Preprints, 2020030277

Kibangou, I. B.; Bouhallab, S.; Henry, G.; Bureau, F.; Allouche, S.; Blais, A.; Guérin, P. Arhan, P. and Bouglé, D. L. (2005). Milk proteins and iron ab-sorption: Contrasting effects of different caseinophosphopeptides. Pediatric Research, 58(4):731-734

Kircheis, R.; Haasbach, E.; Lueftenegger, D.; Heyken,W.T. and Ocker, M.; Planz, O. (2020). NF-kappaB pathway as a potential target for treatment of critical stage COVID-19 patients. Front. Immunol., 11:598444.

Klysz, D.; Tai,X.; Robert, P.A.; Craveiro, M.; Cretenet, G; Oburoglu,L.; Mongellaz, C.; Floess, S. Fritz, V. and Matias, M.I. (2015). Glutamine-dependent alphaketoglutarate production regulates the balance between $\mathrm{T}$ helper 1 cell and regulatory T cell generation. Sci. Signal., 8:doi: 10.1126/ scisignal. aab2610

Kobayashi, E.H.; Suzuki, T.; Funayama, R.; Nagashima, T.; Hayashi, M.; Sekine,H.; Tanaka, N.; Moriguchi, T.; Motohashi, H. and Nakayama, K. (2016). Nrf2 suppresses macrophage inflammatory response by blocking proinflammatory cytokine transcription. Nat. Commun., 7:1162432

Kode, A.; Rajendrasozhan, S.; Caito, S.; Yang, S.R.; Megson, I.L. and Rahman, I (2008). Resveratrol induces glutathione synthesis by activation of Nrf2 and protects against cigarette smoke-mediated oxidative stress in human lung epithelial cells. Am. J. Physiol. Lung Cell Mol. Physiol., 294:L478-L488.

Krinsky, N. I. and Johnson, E. J. (2005). Carotenoid actions and their relation to health and disease. Mol. Aspects Med., 26(6):459-516.

Krinsky, N. I.; Beecher, G. R.; Burk, R. F.; Chan, A. C.; Erdman, J. W. and Jacob, R. A. (2000). Panel on dietary antioxidants and related compounds. Food Nut. Board, National Academy of Sciences, National Academy Press.

Kumar, Brijesh; Zaidi, Sama ; Haque, Shafiul.; Dasgupta, Nandita; Hussain, Arif; Unni, Sreepoorna ; Singh, Vineeta ; Mishra, and Bhartendu Nath. (2020). In silico studies reveal antiviral effects of traditional Indian spices on COVID-19. Curr. Pharma Design :DOI:10.2174/13816128 26666201223095548

Laforge, M.; Elbim, C.; Frere, C.; Hemadi, M.; Massaad, C.; Nuss, P.; Benoliel, J.J. and Becker, C. (2020). Tissue damage from neutrophil induced oxidative stress in COVID-19. Nat. Rev. Immunol., 20:515-516.

Lai ,C.C.; Liu, W.L. and Chen, C.M. (2014). Glutamine attenuates acute lung injury caused by acid aspiration. Nutrients, 6:3101-3116.

Lammi, C.; Aiello, G.; Boschin, G. and Arnoldi, A. (2019). Multifunctional peptides for the prevention of cardiovascular disease: A new concept in the area of bioactive food-derived peptides. Jour. Funct. Foods, 55: $135-145$.

Lee, C.H.; Kim, H.K.; Kim, J.M.; Ayush, O. and Lee, H.K. (2012). Glutamine suppresses airway neutrophilia by blocking cytosolic phospholipase $\mathrm{A}(2)$ via an induction of MAPK phos phatase 1. J. Immunol. 189: 5139-5146.

Leung, W.K.; To, K.; Chan, P.K.S.; Chan, H.L.Y.; Wu, A.K.L.; Lee, N.; Yuen, K.Y. and Sung, J.J.Y. (2003) Enteric involvement of severe acute respiratory syndrome-associated coronavirus infection .Gastroenterology, 125:1011-1017 
Li, Q.; Guan, X.; Wu, P.; Wang, X.; Zhou, L.; Tong, Y. and Feng, Z. (2020). Early transmission dynamics in Wuhan, China, of novel coronavirusinfected pneumonia. New England Journal of Medicine, 382:1199_ 1207.

Li, W.; Maeda, N. and Beck, M. A. (2006). Vitamin C deficiency increases the lung pathology of influenza virus-infected gul mice. Jour. Nutrition, 136(10):261 1-2616.

Li, Y.; Yao, J.; Han, C.; Yang, J.; Chaudhry, M.; Wang, S.; Liu, H. and Yin, Y. (2016). Quercetin, inflammation and immunity. Nutrients, 8(3):167-73.

Li, Y.; Yao, J.; Han, C.; Yang, J.; Chaudhry, M.T.; Wang, S.; Liu, H. and Yin, Y (2016). Quercetin, Inflammation and Immunity. Nutrients, 8:167178

Li,Y.Q.; Li, ZLL.; Zhao, W.J.; Wen, R.X.; Meng, Q.W. and Zeng, Y.(2006). Synthesi of stilbene derivatives with inhibition of SARS coronavirus replication. Eur. J. Med. Chem., 41:1084-1089.

Liang, Y.C.; Tsai, S.H.; Tsai, D.C.; Lin-Shiau, S.Y. and Lin, J.K. (2001). Suppression of inducible cyclooxygenase and nitric oxide synthase through activation of peroxisome proliferator-activated receptor-gamma by flavonoids in mouse macrophages. FEBS Lett; 496(1):12-8.

Lin, S. C.; Ho, C. T.; Chuo, W. H.; Li, S., Wang, T.T. and Lin, C.C. (2017). Effective inhibition of MERS-CoV infection by resveratrol. BMC Infectious Diseases, 17(1):1-10.

Liu,F.; Zhu, Y.; Zhang, J.; Li, Y. and Peng, Z. (2020). Intravenous high-dose vitamin $\mathrm{C}$ for the treatment of severe COVID-19 : Study protocol for a multicentre randomised controlled trial. BMJ Open., 7(08). DOI: $10.1136 /$ bmjopen-2020-039519.

Lopresti, A.L. (2018). The problem of curcumin and its bioavailability: Could its gastrointestinal influence contribute to its overall healthenhancing effects? Advances in Nutrition, 9(1):41-50.

Lordan, R.; Redfern, S.; Tsoupras, A. and Zabetakis, I. (2020). Inflammation and cardiovascular disease: Are marine phospholipids the answer? Food and Function, https://doi.org/gg29hg DOI: 10.1039/ c9fo01742a

Lu, C.C.; Lai, H.C.; Hsieh, S.C.; Chen and J.K., (2008). Resveratrol ameliorates Serratia marcescens - induced acute pneumonia in rats. J. Leukoc Biol., 83:1028-1037.

Luetkemeyer, A. and Kline, S. (2020). Remdesivir for the treatment of COVID19: Preliminary report. New. Engl., 16:20-29.

Luoto, R.; Ruuskanen, O.; Waris, M.; Kalliomaki, M.; Salminen, S. and Isolauri, E. (2014). Prebiotic and probiotic supplementation prevents rhinovirus infections in preterm infants: A randomized, placebocontrolled trial. J. Allergy Clin. Immunol., 133:405-413.

Mahmoud Abulmeaty (2020). Anti-inflammatory/antioxidant oral nutrition supplementation on the cytokine storm and progression of COVID19: A randomized controlled trials. Clinical trials. gov., 09(18)https:/ /clinicaltrials.gov/ct2/show/NCT04323228

Manjeet K, R. and Ghosh, B. (1999). Quercetin inhibits LPS induced nitric oxide and tumor necrosis factor alpha production in murine macrophages. International Journal of Immunopharmacology, 21(7)" 435-443.

Manoharan, Y.; Haridas, V.; Vasanthakumar, K. C., Muthu, S.; Thavoorullah, F. F. and Shetty, P. (2020). Curcumin: A wonder drug as a preventive measure for COVID-19 management. Ind. Journ. Clin. Biochem., 35(3), $373-$ 375
Martínez-Flórez, S.; González-Gallego, J.; Culebras, J.M. and Tuñón, M.J.(2018). Flavonoids: Properties and anti-oxidizing action. Nutr. Hosp., 17: 271-278.

McAleer, J.P. and Kolls, J.K. (2018). Contributions of the intestinal microbiome in lung immunity. Eur. J. Immunol., 48:39-49.

McCarty, M.F. and DiNicolantonio, J.J. (2020). Nutraceuticals have potential for boosting the type 1 interferon response to RNA viruses including influenza and coronavirus. Prog. Cardiovasc. Dis. https://doi.org/ 10.1016/j.pcad.202.02.007

McClements, D.J.: Decker, E.A.; Park, Y. and Weiss, (2009). Structural design principles for delivery of bioactive components in nutraceuticals and functional foods. Critical Reviews in Food Science and Nutrition, 06(16):577-606

Mehta, P.; McAuley, D.F.; Brown, M.; Sanchez, E.; Tattersall, R.S. and Manson, J.J. (2020). All across speciality collaboration, U.K. COVID-19: Consider cytokine storm syndromes and immunosuppression. Lancet, 395:1033-1034.

Meingast, C. and Heldt, C.L. (2020). Arginine enveloped virus inactivation and potential mechanisms. Biotechnol. Prog., 36:e2931.

Mickleborough, T.D.; Tecklenburg, S.L.; Montgomery, G.S. and Lindley, M.R. (2009). Eicosapentaenoic acid is more effective than docosahexae-noic acid in inhibiting proinflammatory mediator production and transcription from LPS-induced human asthmatic alveolar macrophage cells. Clin. Nutr. 28(1):71-77. doi:10.1016/j.clnu.20 08.10.012.

Mikirova, N. A. and Hunninghake, R. (2014). Effect of high dose vitamin C on epstein-barr viral infection. Medical science monitor. International Medical Journal of Experimental and Clinical Research, 20:725-39.

Mlcek, J.; Jurikova, T.; Skrovankova, S. and Sochor, J. (2016). Quercetin and its anti-allergic immune response. Molecules, 21:623.

Molina, N.; Morandi, A.C.; Bolin, A.P. and Otton, R. (2014). Comparative effect of fucoxanthin and vitamin $\mathrm{C}$ on oxidative and functional parameters of human lymphocytes. Int. Immunopharmacol., 22:4150

Moore Patrick.; Rashida, G.; Revuri, N.; Kranz, V.A., Houle, J.D.; Khan, Z. K. and Jain, P. (2017), Nutraceutical apigenin: Mechanism of action associated with its anti-inflammatory activity and regulation of dendritic cell metabolism, Jour. Immunol., 198:219-27.

Morita, M.; Kuba, K.; Ichikawa, A.; Nakayama, M.; Katahira,J.; Iwamoto, R.; Watanebe, T. and Sakabe, S.(2013). The lipid mediator protectin D1 inhibits influenza virus replication and improves severe influenza. Cell, 03:DOI: 10.1016/j.cell.2013.02.027.

Moser, M.A.; and Chun, O.K. (2016). Vitamin C and heart health: A review based on findings from epidemiologic studies. Int. J. Mol. Sci., 17: 1328-38.

Murphy, E.J.; Masterson, C.; Rezoagli,E.; O’Toole, D.; Major, I.; Stack, G.D.; Lynch, M.; Laffey, J.G. and Rowan, N.J. (2020) $\beta$ Glucan extracts from the same edible shiitake mushroom Lentinus edodes produce differential in vitro immunomodulatory and pulmonary cytoprotective effects Implications for coronavirus disease (COVID-19) immunotherapies. Sci. Total Environ., 732:139-330.

Naithani, R.; Huma, L. C.; Holland, L. E.; Shukla, D.; Mc Cormick, D.L.; Mehta, R. G. and Moriarty, R.M. (2008). Antiviral activity of phytochemicals: A comprehensive review. Mini Reviews in Medicinal Chemistry, 8(11): 1106-1133.

Nakaya, M.; Xiao,Y.; Zhou, X.; Chang, J.H.; Chang, M.; Cheng, X.; Blonska, M.; Lin, $X$. and Sun, S.C. (2014). Inflammatory $T$ cell responses rely on amino acid transporter ASCT2 facilitation of glutamine uptake and mTORC1 kinase activation, Immunity, 40:692-705. 
Namba, K.; Hatano, M.; Yaeshima, T.; Takase, M. and Suzuki, K. (2010). Effect of Bifidobacterium longum BB536 administration on influenza infection, influenza vaccine antibody titer, and cell-mediated immunity in the elderly. Biosci. Biotechnol. Biochem., 74:939-45.

Nature Reviews Cardiology 07(07): DOI: 10.1038/nrcardio.2016.103. PMID: 27383080.

Nicholas, C. Batra, S. and Vargo, M.A. (2007). Apigenin blocks lipopolysaccharide-induced lethality in vivo and proinflammatory cytokines expression by inactivating NF- $\mathrm{kB}$ through the suppression of p65 phosphorylation. J. Immunol., 179(10):7121-7127. doi: 10.4049/jimmunol.179.10.7121

Nielsen, S.E.; Young, J.F.; Daneshvar, B.; Lauridsen, S.T.; Knuthsen, P.; Sandström, B. and Dragsted, L.O. (1999). Effect of parsley (Petroselinum crispum) intake on urinary apigenin excretion, blood antioxidant enzymes and biomarkers for oxidative stress in human subjects. $\mathrm{Br}$. J. Nutr., 81:447-455.

Nieman, D.C.; Henson, D.A.; Davis, J.M.; Murphy, E.A.; Jenkins, D.P.; Gross, S.J.; Carmichael, M.D.; Quindry, J.C.; Dumke, C.L. and Utter, A.C. (2007). Quercetin's influence on exercise-induced changes in plasma cytokines and muscle and leukocyte cytokine mRNA. J. Appl. Physiol., 103:1728-1735.

Nieman, D.C.; Williams, A.S.; Shanely, R.A.; Jin, F.; Mcanulty, S.R.; Triplett, N.T.; Austin, M.D. and Henson, D.A. (2010). Quercetin's influence on exercise performance and muscle mitochondrial biogenesis. Med. Sci. Sports Exerc., 42:338-345.

Ohtake, S; Arakawa, T. and Koyama, A.H. (2020). Arginine as a syner gistic virucidal agent. Molecules, 15:1408-1424.

Olagnier, D.; Farahani, E.; Thyrsted, J.; Blay-Cadanet, J.; Herengt, A.; Idorn, M.; Hait, A.; Hernaez, B.; Knudsen, A. and Iversen, M.B. (2020). SARS-CoV2mediated suppression of NRF2-signaling reveals potent antiviral and anti-inflammatory activity of 4-octyl-itaconate and dimethyl fumarate. Nat. Commun., 11:49-38.

Oliveira, G.P.; De Abreu, M.G; Pelosi, P. and Rocco, P.R. (2016). Exogenous glutamine in respiratory diseases: Myth or reality? Nutrients, 8:76.

Pal, A.; Gowdy, K.M.; Oestreich, K.J.; Beck, M. and Shaikh, S.R. (2020). Obesitydriven deficiencies of specialized pro-resolving mediators may drive adverse outcomes during SARS-CoV-2 infection frontiers in Immunology, 8(11):DOI:10.3389/fimmu.2020.01997.

Palamara,A.T.; Nencioni, L.; Aquilano, K.; De Chiara, G.; Hernandez, L.; Cozzolino, F.; Ciriolo, M.R. and Garaci, E. (2005). Inhibition of influenza A virus replication by resveratrol. J. Infect. Dis., 191:1719-1729.

Pang, X.; Zhang, L.; Bai, F.;Wang, N.; Garner, R.E.; McKallip, R.J. and Zhao, Z.Q. (2015). Attenuation of myocardial fibrosis with curcumin is mediated by modulating expression of angiotensin II AT 1/AT2 receptors and ACE2 in rats. Drug Des. Dev. Ther., 9:6043-6054

Panigrahi, P.; Parida, S.; Nanda, N.C.; Satpathy, R.;,Pradhan, L. and Chandel, D.S (2017). A randomized synbiotic trial to prevent sepsis among infants in rural India. Nature, 548:407-12.

Panigrahy, D.; Gilligan, M.M.; Huang, S.; Gartung, A.; Puch, I. and Patricia J., Hammock, B.D. (2020). Inflammation resolution: A dual-pronged approach to averting cytokine storms in COVID-19? Cancer and Metastasis Reviews,05(08):DOI: 10.1007/s10555-020-09889-4.

Paolino N.; Antonella, A.; Magnani, M. and Emanuele, S. (2020). Antiviral properties of flavonoids and delivery strategies. Nutrients, 12:2534 2547.

Pendyala, B. and Patras, A. (2020). In silico screening of food bioactive compounds to predict potential inhibitors of COVID-19 main protease (Mpro) and RNA-dependent RNA polymerase (RdRp). Chem. Rxiv. Preprint.
Pierre, J.F.; Heneghan,A.F.; Lawson, C.M.; Wischmeyer, P.E.; Kozar, R.A. and Kudsk K.A. (2013). Pharmaconutrition review: Physiological mechanisms. JPEN J. Parenter. Enteral. Nutr., 37:51-65.

Praditya, D.; Kirchhoff, L.; Brüning, J.; Rachmawati, H.; Steinmann, J. and Steinmann, E. (2019). Anti-infective properties of the golden spice curcumin. Front. Microbiol., 10:912-920.

Prasad, K.; Fatima.K.; Summya, R.; Ali, N.; Abdullah, F.A.; Mohammad, Z. A.; Ali, S.; Mohammed, S.; Alqahtani and Kumara, V. (2020). Targeting hub genes and pathways of innate immune response in COVID-19: A network biology perspective. Int. J. Biol. Macromol., 15(163):1-8.

Prompetchara, E.; Ketloy, C. and Palaga, T. (2020). Immune responses in COVID19 and potential vaccines: Lessons learned from SARS and MERS epidemic. Asian Pac. J. Allergy Immunol., 38:1-9.

Qin, C.; Zhou, L.; Hu, Z.; Zhang, S.; Yang, S.; Tao, Y.; Xie, C.; Ma, K.; Shang, K.; Wang, W. and Tian, D.S. (2020). Dysregulation of immune response in patients with COVID-19 in Wuhan, China. Clin. Infect. Dis. pii, ciaa248. 10.1093/cid/ciaa248.

Quiles, J. L.; Rivas-García, L.; Varela-López, A.; Llopis, J.; Battino, M. and SánchezGonzález, C. (2020). Do nutrients and other bioactive molecules from foods have anything to say in the treatment against COVID-19 ? Env. Res., 191, 110053.

Rajasekaran, A.; Sivagnanam, G.; and Xavier, R. (2008). Nutraceuticals as therapeutic agents. A Review. Res. J. Pharm. Sci. Technol., 1(4):328340 .

Ramírez-Garza, S. L.; Laveriano-Santos, E. P.; Marhuenda-Mu Pnoz, M.;Storniolo, C. E.;Tresserra-Rimbau, A. and Vallverdú-Queralt, A. (2018). Health effects of resveratrol: Results from human intervention trials. Nutrients, 10(12): 1892 .

Ramon, s.; Baker, S.F.; Sahler, J.M.; Kim,N.; Feldsott, E.A.; Serhan, C.N.; Sobrido, L.M.; Topham, D.J. and Phipps, R.P. (2014). The specialized proresolving mediator 17-HDHA enhances the antibody-mediated immune response against influenza Virus: A new class of adjuvant? Jour. Immuno., 12B:DOI: 10.4049/jimmunol.1302795.

Ratha, S.K.; Renuka, N.; Rawat, I. and Bux, F., (2021). Prospective options of algae-derived nutraceuticals as supplements to combat COVID-19 and human coronavirus diseases. Nutrition, 03: https://doi.org/ ghr93z. DOI: $10.1016 /$ j.nut.2020.111089.

Rautava, S.; Salminen, S. and Isolauri, E. (2009). Specific probiotics in reducing the risk of acute infections in infancy: A randomised, double-blind, placebo-controlled study. Br. Jour. Nutr., 101:1722-1726.

Regidor, P.A.; Santos, F.G.; Rizo, J.M. and Egea, F.M. (2020). Pro-resolving inflammatory effects of the lipid mediators of omega 3 fatty acids and its implication in SARS COVID-19. Medical Hypotheses, 12: DOI: $10.1016 /$ j.mehy.2020.110340

Rodríguez-Valentín, M.; López, S.; Rivera, M.; Ríos-Olivares, E.; Cubano, L. and Boukli, N.M. (2018). Naturally derivedanti-HIV polysaccharide peptide (PSP) triggers a toll-like receptor 4-dependent antiviral immune response. J. Immunol. Res., 20(18): 1-15

Rucker, R.B.; Morris, J. and Fascetti, A. (2008). Vitamins, in Clinical biochemistry of domestic animals, 6th edn Academic Press, New York, p. 695-730

Runfeng, L.; Yunlong, H.; Jicheng, H.; Weiqi, P.; Qinhai, M.; Yongxia, S.; Chufang, L.; Jin, Z; Zhenhua, J. and Haiming, J., (2020). Lianhuaqingwen exerts anti-viral and anti-inflammatory activity against novel coronavirus (SARS-CoV-2). Pharmacol. Res., 156, 104761.

Russell, B.; Moss, C.; Rigg, A. and Van Hemelrijck, M., (2020). COVID-19 and treatment with NSAIDs and corticosteroids: Should we be limiting their use in the clinical setting? Ecancermedicalscience 2020, 14: 112-117. 
S.L.A. Pharma AG (2020). Randomised, double-blind, placebo controlled study of eicosapentaenoic acid. Reviews, 10:27-30.

Sabater, J.; Masclans, J.; Sacanell, J.; Chacon, P.; Sabin, P. and Planas.M. (2011) Effects of an omega-3 fatty acid-enriched lipid emulsion on eicosanoid synthesis in acute respiratory distress syndrome (ARDS): A prospective, randomized, double-blind, parallel group study. Nut. and Meta.:DOI:10.1186/1743-7075-8-22.

Saha, S. and Murray, P. (2018). Exploitation of microalgae species for nutraceutical purposes: Cultivation aspects fermentation, 06 (14)https://doi.org/ghv64j , DOI: 10.3390/fermentation4020046

Salehi, B.; Venditti, A.; Sharifi-Rad, M.; Kregiel, D.; Sharifi-Rad, J.; Durazzo, A.; Lucarini, M.; Santini, A.; Souto, E.B. and Novellino, E. (2019). The therapeutic potential of apigenin. Int. J. Mol. Sci., 20:1305-1319.

Sandhaus, S. and Swick, A.G. (2020). Specialized mediators in infection and lung injury. BioFactors, 11(28): https://doi.org/ghr93m

Santoyo, L. S. and Jaime, M. Plaza (2012). Antiviral compounds obtained from microalgae commonly used as carotenoid sources. J. Appl. Phycol., 24:731-741.

Sayed, A.M.; Khattab, A.R.; AboulMagd, A.M.; Hassan, H.M.; Rateb, M.E.; Zaid, H. and Abdelmohsen, U.R., (2020). Nature as a treasure trove of potential anti-SARS-CoV drug leads: A structural/mechanistic rationale. RSC Adv., 10:19790-19802.

Schuijt, T.J.; Lankelma, J.M.; Scicluna, B.P.; de Sousae Melo F.; Roelofs, J.J. and de Boer JD. (2016). The gut microbiota plays a protective role in the host defence against pneumococcal pneumonia. Gut., 65:575-583.

Schwarz S.; SauterD.; Wang K.; Zhang R.; Sun B.; Karioti A.; BiliaA R.; EfferthT.a and Schwarz W.,(2014). Kaempferol derivatives as antiviral drugs against the 3 a channel protein of coronavirus. Planta. Med. 80(2-3): 177-182. doi: $10.1055 / \mathrm{s}-0033-1360277$

Serhan, C.N. (2014). Pro-resolving lipid mediators are leads for resolution physiology. Nature, 06(04): DOI: 10.1038/nature13479

Seri J., Suwon K., Dong H S., and Mi-S K., (2020). Inhibition of SARS-CoV 3CL protease by flavonoids, J. Enzyme. Inhib. Med. Chem., 35(1):145151

Shim, J.S.; Kim, J.H.; Cho, H.Y.; Yum, Y.N.; Kim, S.H.; Park, H.J.; Shim, B.S.; Choi, S.H. and Kwon, H.J., (2003). Irreversible inhibition of CD13/ aminopeptidase $\mathrm{N}$ by the antiangiogenic agent curcumin. Chem. Biol., 10: 695-704.

Shimon Ben-Shabat, Ludmila Yarmolinsky, Daniel Porat and Arik Dahan (2019). Antiviral effect of phytochemicals from medicinal plants: Applications and drug delivery strategies; Drug Delivery and Translational Research, 10:354-367.

Suravajhala, R.; Parashar, A.; Malik, B.; Nagaraj, V.A.; Padmanaban, G.; Kavi Kishor, P.; Polavarapu, R. and Suravajhala, P. (2020). Comparative docking studies on curcumin with COVID-19 proteins. Preprints, 2020, 2020050439 (doi: 10.20944/preprints202005.0439.v3).

Shin, H.S.; See, H.J.; Jung, S.Y.; Choi, D.W.; Kwon, D.A.; Bae, M.J.; Sung, K.S. and Shon, D.H. (2015). Turmeric (Curcuma longa) attenuates food allergy symptoms by regulating type 1/type 2 helper $\mathrm{T}$ cells (Th1/Th2) balance in a mouse model of food allergy. J. Ethnopharmacol., 175:21-29.

Sinclair, L.V.; Rolf, J.; Emslie, E.; Shi, Y.B.; Taylor, P.M. and Cantrell, D.A. (2013). Control of amino-acid transport by antigen receptors coordinates the metabolic reprogramming essential for $\mathrm{T}$ cell differentiation. Nat. Immunol., 14:500-508

Skarke, C.; Alamuddin, N.; Lawson, J.A.; Li, X.; Ferguson, Muredach P.: Reilly, G.A. and Gerald, F.; (2016). Bioactive products formed in humans from fish oils. Jour. Lipid Res., 09: DOI:10.1194/jlr.m060392.
Soleimani, V.; Sahebkar, A. and Hosseinzadeh, H. (2018). Turmeric (Curcuma longa) and its major constituent (curcumin) as nontoxic and safe substances. Phytotherapy Research, 32(6):985-995.

Stewart, L.K.; Soileau, J.L.; Ribnicky, D.; Wang, Z.Q.; Raskin, I.; Poulev, A.; Majewski, M.; Cefalu, W.T. and Gettys, T.W. (2008). Quercetin transiently increases energy expenditure but persistently decreases circulating markers of inflammation in C57BL/6J mice fed a high-fat diet. Metabolism, 57:39-46.

Stier, H.; Ebbeskotte, V. and Gruenwald, J., (2014). Immune-modulatory effects of dietary Yeast Beta-1,3/1,6-D-glucan. Nutr. J., 13:38-45.

Strasser, B.; Geiger, D.; Schauer, M.; Gostner, J.M.; Gatterer, H.; Burtscher, M. and Fuchs, D. (2016). Probiotic supplements beneficially affect tryptophan kynurenine metabolism and reduce the incidence of upper respiratory tract infections in trained athletes: A randomized, double blinded, placebo controlled trial. Nutrients, 8:752-766.

Sui, H.; Yu, Q.; Zhi, Y.; Geng, G.; Liu, H. and Xu, H. (2010). Effects of apigenin on the expression of angiotensin-converting enzyme 2 in kidney in spontaneously hypertensive rats. J. Hyg. Res., 39:693-696.

Swanson, K.S.; Gibson, G. R.; Hutkins, R.; Reimer, R.A.; Reid, G.; Verbeke, K.; Scott, K.P.; Holscher, H.D.; Azad, M.B. and Delzenne,N.M. (2020). The international scientific association for probiotics and prebiotics (ISAPP) consensus statement on the definition and scope of synbiotics. Nat. Rev. Gastroenterol. Hepatol., 17:687-701.

Szabó, Z.; Marosvölgyi, T.; Szabó, E.; Bai,P.; Figler, M. and Verzár, Z. (2020). The potential beneficial effect of EPA and DHA supplementation managing cytokine storm in coronavirus disease. Front. Phy., https:/ /doi.org/gg4hz4

T"ozsér, J. and Benk"o, S. (2016). Natural compounds as regulators of NLRP3 inflammasome-mediated IL-1 production. Mediat. Inflamm., 5460302.

Tallei, T.E.; Tumilaar, S.G.; Niode, N.J.; Fatimawali, F.; Kepel, B.J.; Idroes, R. and Effendi, Y. (2020). Bioactive compounds as SARS-CoV-2 main protease (Mpro) and spike (S) glycoprotein inhibitors: A molecular docking study. Hindawi Scientifica, Article ID 6307457, 18 pages.

Tapas, A.R.;Sakarkar, D.M. and Kakde, R.B. (2008). Flavonoids as nutraceuticals: A review; Tropical Journal of Pharmaceutical Research, 7(3):1089-1099

Thevarajan, I.; Nguyen, T.H.O. and Koutsakos, M. (2020). Breadth of concomitant immune responses prior to patient recovery: A case report of non-severe COVID-19. Nat. Med. 26:453-455.

Tsujimoto, K.; Uozaki, M.; Ikeda, K.; Yamazaki, H.; Utsunomiyam H.; Ichinose, M.; Koyamam, A.H. and Arakawa, T. (2010). Solvent induced virus inactivation by acidic arginine solution. Int. J. Mol. Med., 25:433 437.

Udenigwe, C. C. and Aluko, R. E. (2012). Food protein-derived bioactive peptides: Production, processing, and potential health benefits. Jour. Food Sci., 77(1):R11-R24.

Ungvari, Z.; Bagi, Z.; Feher,A.; Recchia, F.A.; Sonntag, W.E.; Pearson, K.; de Cabo, R. and Csiszar, A. (2010). Resveratrol confers endothelial protection via activation of the antioxidant transcription factor Nrf2. Am. J. Physiol. Heart Circ. Physiol., 299:H18-H24.

Upadhyay, R.K. (2016). Anti-arthritic potential of plant natural products; its use in joint pain medications and anti-inflammatory drug formulations. Int. J. Green Pharm., 10:111-119

Urbancikova, I.; Hudackova, D.; Majtan, .; Rennerova, Z.; Banovcin, P. and Jesenak, M. (2020). Efficacy of Pleuran ( $\beta$ Glucan from Pleurotusostreatus) in the management of herpes simplex virus type 1 infection. Evid Based Complement Alternat. Med.: https://doi.org/10.1155/2020/ 8562309 . 
Utomo, R. Y.; Ikawati, M. and Meiyanto, E. (2020). Revealing the potency of citrus and galangal constituents to halt SARS-CoV-2 infection. Preprints 2020, 2020030214: doi: 10.20944/preprints202003. 0214.v1.

Verma Garima and Mishra M.K. (2016). A review on nutraceuticals: classification and its role in various diseases. International Journal of Pharmacy and Therapeutics, 7(4):152-160.

Verma, S.K. (2020). In Search of Feasible Interventions for the Prevention and Cure of Novel Coronavirus Disease 2019 Preprints, 2020030353:doi: 10.20944/preprints202003.0353.v1.

Vetvicka, V. and Vetvickova J. (2014) . Comparison of immunological effects of commercially available $\beta$-glucans. Appl. Sci. Rep., 1:2-15.

Vetvicka, V. and Vetvickova J. (2016) . Comparison of immunological effects of commercially available beta-glucans: part III. Int. Clin. Pathol. J., 2:78-83

Villa-Rodriguez, J.A.; Kerimi ,A.; Abranko, L.; Tumova, S.; Ford, L.; Blackburn, R.S.; Rayner, C. and Williamson, G. (2018). Acute metabolic actions of the major polyphenols in chamomile: An in vitro mechanistic study on their potential to attenuate postprandial hyperglycaemia. Sci. Rep., 8(1):5471-5182.

Vitaglione, P.; Sforza, S.; Galaverna, G.; Ghidini, C.; Caporaso, N. and Vescovi, P. P. (2005). Bioavailability of trans-resveratrol from red wine in humans. Molecular Nutrition and Food Research, 49(5):495-504.

Wahedi, H.M.; Ahmad, S. and Abbasi, S.W. (2020). Stilbene-based natural compounds as promising drug candidates against COVID-19 . J. Biomol. Struct. Dyn., 20:1-10.

Walston,J.; Xue, Q.; Semba, R. D.; Ferrucci, L.; Cappola, A. R.; Ricks, M.; Guralnik, J. and Fried, L. P. (2006). Serum antioxidants, inflammation, and tota mortality in older women. Amer. Jour. Epidemiology, 163(1):18 26.

Walters, M. E.; Esfandi, R. and Tsopmo, A. (2018). Potential of food hydrolyzed proteins and peptides to chelate iron or calcium and enhance their absorption. Foods, 7(10):172.

Wang, F.; Hou, H.; Luo, Y.; Tang, G; Wu, S.; Huang, M.; Liu, W.; Zhu, Y.; Lin, Q.; Mao, L.; Quiles, G.M.; Zhang, H. and Sun, Z. (2020). The laboratory tests and host immunity of COVID-19 patients with different severity of illness. JCI Insight, 137799. https://doi.org/10.1172/jci.insight. 137799

Wei Zhang, HaishiQiao, YuanziLv, Jingjing Wang, Xiaoqing Chen, Yayi Hou and Renxiang Tan. (2014). Apigenin inhibits enterovirus-71 infection by disrupting viral RNA association with trans-acting factors. Plos One, October 16, 2014; https://doi.org/10.1371/journal.pone. 0110429

Weiss, B.; Bujanover, Y.; Yahav, Y.;,Vilozni, D.; Fireman, E. and Efrati, O.(2010) Probiotic supplementation affects pulmonary exacerbations in patients with cystic fibrosis: a pilot study. Pediatr Pulmonol., 45:536-40.

Wen-Chao, Song.; Garret, A. and Fitz Gerald. (2020) COVID-19, microangiopathy, hemostatic activation, and complement. Jour. Clin. Invest., 6(22):DOI: 10.1172/.

Wenzel, E and Somoza, V., (2005). Metabolism and bioavailability of transresveratrol. Molecular Nutrition and Food Research, 49(5):472481

Xu, D.; Hu, M. J.; Wang, Y. Q. and Cui, Y. L. (2019). Antioxidant activities of quercetin and its complexes for medicinal application. Molecules, 24(6): $1123-1131$
Yamasaki H.; Tsujimoto, K.; Koyama, A.H.; Ejima, D. and Arakawa, T. (2008). Arginine facilitates inactivation of enveloped viruses. J. Pharm. Sci. 97:3067-3073.

Yamasaki, Hisashi .; Tsujimoto, Kazuko.; Ikeda, Keiko .; Suzuki, Yukiko.; Tsutomu Arakawa. and Hajime Koyama. (2011). Antiviral and virucidal activities of N5Ø6ß-cocoyl-L-arginine ethyl ester. Advances in Virology, Volume 2011, Article ID 572868, https://doi.org/10.1155/2011/ 572868 .

Yamada, K.; Ogawa H.; Hara, A.; Yoshida,Y.;Yonezawa, Y.;Karibe, K.;Nghia, V. B.; Yoshimura, H.; Yamamoto, Y. U.; Yamada, M.; Nakamura, K. and Imai, K. (2009). Mechanism of the antiviral effect of hydroxyty-rosol on influenza virus appears to involve morphological change of the virus. Antiviral Research, 83(1):35-44.

Yang, C.; Yang,W.; He, Z.; He, H.; Yang, X.; Lu, Y. and Li, H. (2020). Kaempferol improves lung ischemia-reperfusion injury via anti-inflammation and antioxidative stress regulated by SIRT1/HMGB1/NF- $\mathrm{BB}$ axis. Front Pharmacol., 10:16-35.

Yang, M.; Wei, J.; Huang, T.; Lei, L.; Shen, C.; Lai, J.; Yang, M.; Liu, L.; Yang, Y. and Liu, G. (2020). Resveratrol inhibits the replication of severe acute respiratory syndrome coronavirus 2 (SARS-CoV-2) in cultured Vero cells. Phytother. Res.: doi: 10.1002/ptr.6916

Zahedipour, F.; Hosseini, S. A.; Sathyapalan, T.; Majeed, M.; Jamialahmadi, T. and Al-Rasadi, K. (2020). Potential effects of curcumin in the treatment of COVID-19 infection. Phytotherapy Research, 20:72-80.

Zelaya, H.; Alvarez, S.; Kitazawa, H. and Villena, J. (2016). Respiratory antiviral immunity and immunobiotics: beneficial effects on inflammationcoagulation interaction during influenza virus infection. Front Immunol., 7:633-641.

Zhang, R,; Kubo, M.; Murakami, I.; Setiawan, H.; Takemoto, K.; Inoue, K.; Fujikura, Y. and Ogino, K. (2015). 1 Arginine administration attenuates airway inflammation by altering 1 arginine metabo lism in an $\mathrm{NC} /$ Nga mouse model of asthma. J. Clin. Biochem. Nutr., 56:201-207.

Zhang, B.; Zhou, X.; Qiu, Y.; Song, Y.; Feng, F.; Feng, J.; Song, Q.; Jia, Q. and Wang, J. (2020) . Clinical characteristics of 82 cases of death from COVID19. PLOS ONE, 70 (09): DOI: 10.1371/journal.pone.0235458

Zhang, H.; Kang, Z; Gong, H.; Xu, D.; Wang, J.; Li,Z.; Cui, X.; Xiao, J.; Meng, T. and Zhou, W. (2020). The digestive system is a potential route of 2019nCov infection: A bioinformatics analysis based on single-cell transcriptomes. BioRxiv, doi: https://doi.org/10.1101/2020.01. 30.927806.

Zhang, Lei.; Yunhui, Liu, (2020). Potential interventions for novel coronavirus in China: A systematic review. J. Med. Virology, 03(03): DOI: $10.1002 /$ jmv. 25707

Zhang, R.; Ai, X.; Duan, Y.; Xue, M.; He, W.; Wang, C.; Xu, T.; Xu, M.; Liu, B. and Li, C. (2017). Kaempferol ameliorates H9N2 swine influenza virusinduced acute lung injury by inactivation of TLR4/MyD88-mediated NF- $\kappa \mathrm{B}$ and MAPK signaling pathways. Biomed. Pharmacother., 89:660-672.

Thong, Q.; Li, X.; Hu, W.; Zeng, B.; Liang, R.; Liu, H.; Li, Z and Zhang, Z.(2016) Phosvitinphosphopeptide preparation using immobilised trypsin and enhancing calcium absorption in growing rats. Czech. Jour. of Food Sc., 34(4):325-331

Zhou, Z.; Zhang, Y.; Lin, L. and Zhou, J. (2018). Apigenin suppresses the apoptosis of $\mathrm{H} 9 \mathrm{C} 2$ rat cardiomyocytes subjected to myocardial ischemia reperfusion injury via upregulation of the PI3K/Akt pathway. Mol. Med. Rep., 18(2):1560-1570. 